\title{
Biases in Variance of Decomposed Portfolio Returns
}

\author{
Vitali Alexeev ${ }^{\sharp}, *$ Katja Ignatieva ${ }^{\natural}$ \\ \# Finance Discipline Group, UTS Business School, University of Technology Sydney \\ Sydney, New South Wales 2007, Australia \\ 4 School of Risk \& Actuarial Studies, University of New South Wales, \\ Sydney, New South Wales 2052, Australia
}

23rd May 2020

\begin{abstract}
Significant portfolio variance biases arise when contrasting multi-period portfolio returns based on the assumption of fixed continuously rebalanced portfolio weights as opposed to buy-and-hold weights. Empirical evidence obtained using S\&P500 constituents from 2003 to 2011 demonstrates that, compared with a buy-and-hold assumption, applying fixed weights led to decreased estimates of portfolio volatilities during 2003, 2005 and 2010, but caused a significant increase in volatility estimates in the more turbulent 2008 and 2011. This discrepancy distorts assessments of portfolio risk-adjusted performance when inappropriate weight assumptions are employed. Consequently, these variance biases have effect on statistical inference in factor models and may result in erroneous portfolio size recommendations for adequate diversification.
\end{abstract}

Keywords: Portfolio diversification, buy-and-hold strategy, portfolio risk, high-frequency data.

JEL: G11, C58, C63

\footnotetext{
*Corresponding author: Email: vitali.alexeev@uts.edu.au; Phone: +61 295147781 . We would like to thank Simon Hayley, Justine Pedrono and Ralph Stevens for helpful comments and discussions. We are grateful for comments from participants and discussants at the 2014 Auckland Finance Meeting, the 2015 Western Economic Association Meeting, the 2015 Canadian Economic Association Conference, the 2015 Quantitative Methods in Finance Meeting, the 2016 New Zealand Finance Colloquium, and the 2016 INFINITI Conference in Dublin. We appreciate the funding and support of the Accounting and Finance Association of Australia and New Zealand.
} 


\section{Introduction}

A common approach in the finance literature for calculating multi-period portfolio returns is to adopt a rebalancing strategy that maintains a fixed weight of each asset in a portfolio at any time. ${ }^{1}$ In contrast, if a buy-and-hold strategy is assumed, asset weights may result in allocations far from the initial distribution when price fluctuations of some portfolio constituents outperform others. This is especially pertinent for longer investment horizons. To illustrate this, Figure 1 presents portfolio weight dynamics for the fixed weight (continuous rebalancing) and the buy-and-hold strategies. For a selection of stocks in the top panels, both strategies maintain similar allocations over time and any differences in portfolio mean returns and portfolio variances are expected to be negligible. On the contrary, the bottom panels show that for a different selection of stocks in the portfolio, the buy-and-hold strategy may lead to a portfolio that is not well diversified (right bottom panel). In fact, one could argue that this portfolio behaves similar to a two-stock portfolio towards the end of the period. In this case, large biases in both the average portfolio return and the portfolio variance may be expected. ${ }^{2}$ In evaluating portfolio performance using multi-period portfolio returns, an appropriate assumption on asset weights must be employed to avoid biases in estimates of the first and second moments of portfolio returns. Estimates of portfolio average return and risk will depend on whether the assumption of fixed or buy-and-hold weights is employed. Buy-and-hold weights ensure that compounding the decomposed multi-period portfolio returns yields the returns earned by an investor who holds the portfolio. In contrast, studies that employ fixed portfolio weights for simplicity, often inadvertently assume a rebalancing frequency matching that of the data used for analysis. For example, an equally weighted portfolio is often calculated as the arithmetic average of individual stock returns in periods corresponding to the frequency of the return data (monthly, weekly, daily, or at higher frequencies). In practice, rebalancing on daily, or perhaps even weekly or monthly, basis to maintain portfolio weights in equal proportion might not be viable.

By comparing rebalanced returns with decomposed buy-and-hold returns, Liu and Strong [2008] find that rebalancing assumption causes an upward bias to the size premium and a downward bias to the momentum effect. Through empirical exercise, the authors show that the two methods can produce a portfolio return difference of more than $8 \%$ per year, and can lead to different statistical inferences.

Inspired by this conjecture, we extend the analysis to the second moment and argue that, in the mean-variance framework, considering only the first moment of portfolio return distribution may result in incomplete judgement with respect to portfolio risk, the importance

\footnotetext{
${ }^{1} \mathrm{~A}$ few notable works that apply a rebalancing method to calculate multi-period portfolio returns include Fama and French [1996], Carhart [1997], Daniel et al. [1997], Lee and Swaminathan [2000], along with more recent ones of Chan et al. [2002], Ahn et al. [2003], Teo and Woo [2004], Cohen et al. [2005], Nagel [2005], Diether et al. [2009], Huang et al. [2010], Hou et al. [2011].

${ }^{2}$ We use the term bias to define the discrepancy in portfolio mean return and variance estimates when using the fixed weight (continuous rebalancing) versus the buy-and-hold strategies thus retaining the definition set out in Liu and Strong [2008].
} 
Figure 1: PORTFOlio WeIGHT DYNAMICS FOR REBALANCED (LEFT PANELS) AND BUY-AND-HOLD (RIGHT PANELS) STRATEGIES. Stocks are allocated equal proportions at inception. The rebalancing is performed daily while the buy-and-hold portfolios are held for the entire period.

(a) Small bias example. Portfolio comprises AEP.N, AIG.N, AIV.N, AMGN.OQ, APA.N, APC.N, APH.N, ASH.N (company names associated with the listed RIC codes can be found in the supplementary online appendix). Provided they had been active for the full period from January 2003 to December 2011, stocks were chosen in alphabetical order. Biases in portfolio mean return and portfolio variance are expected to be negligible since both strategies maintain similar portfolio composition throughout the period.
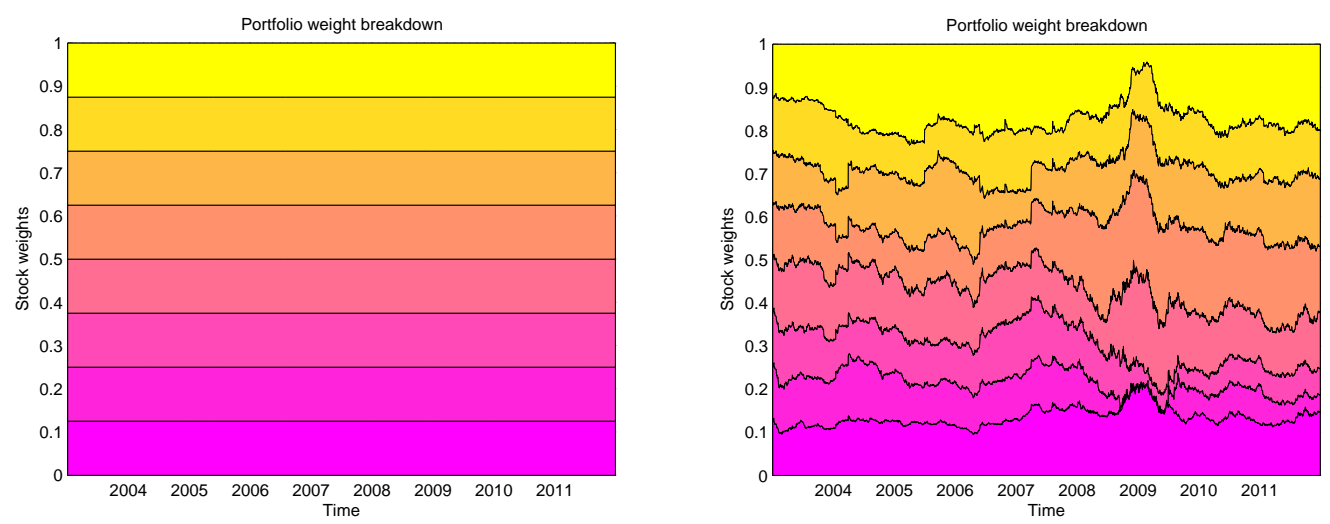

(b) LARge biAs EXAMPLE. AKAM.OQ and ATI.N are added to the list of 8 stocks in the panel above. The buy-and-hold portfolio (on the right) is not as well-diversified as the rebalanced portfolio (on the left). Large biases in portfolio mean return and portfolio variance are expected.
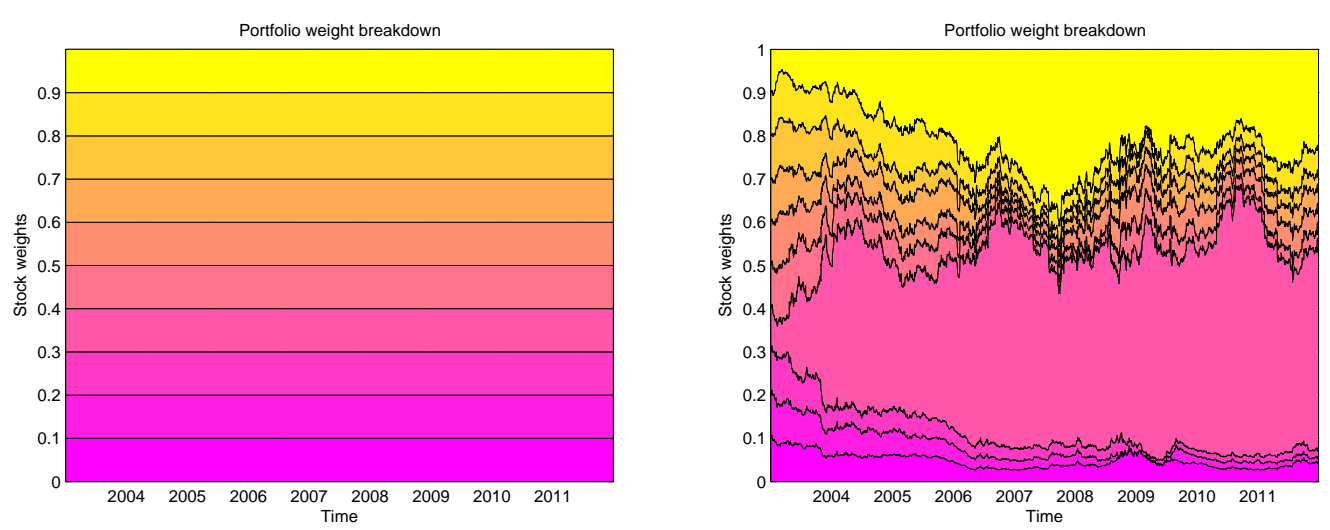

of common market factors, and, therefore, investment decisions. We show that employing a wrong assumption on weights in decomposition of portfolio returns leads to significant discrepancies in portfolio variance estimates. In turn, this may result in erroneous inference about portfolio risk or risk-adjusted portfolio performance. The importance of biases in portfolio variance cannot be overstated. In the last two decades, empirical studies began to rely on data at higher frequencies in evaluating portfolio performance or testing asset pricing models; the portfolio rebalancing frequency may be catching up but at a much slower pace. $^{3}$

Indisputably, a buy-and-hold assumption would be more practical for individual in-

\footnotetext{
${ }^{3}$ Data at higher frequencies demonstrably improves the estimation of risk. A range of efficient estimators has been developed offering a more accurate estimation of financial risk (see McAleer and Medeiros [2008] for a survey on realized estimators). This is also in line with Fama and French [1998, p.1977] who argue that the "annual returns suffice for estimating expected returns, but tests of asset pricing models (which also require second moments) are hopelessly imprecise unless returns for shorter intervals are used".
} 
vestors. ${ }^{4}$ On the other hand, fixed portfolio weight assumption is dominant in portfolio literature. Due to simplicity and tractability of the approach, authors adopting this strategy seem to ignore the associated biases when evaluating buy-and-hold portfolios. Approximate results from a rebalancing strategy "...may suffice for a quick and coarse comparison of investment performance across many assets, but for finer calculations in which the volatility of returns plays an important role ... the approximation may break down." [Campbell et al., 1997, p.10]. Starting from the earlier studies by Roll [1984], Blume and Stambaugh [1983] and Conrad and Kaul [1993] that outline the presence of market microstructure biases and recommend the use of buy-and-hold returns, the recent work by Liu and Strong [2008] discusses in detail the existence of biases resulting from applying the rebalancing method to buy-and-hold portfolios in the U.S. equity market. The authors analyse portfolio returns over a multi-period holding horizon and compute the bias of the portfolio mean return in each month as the difference between the average rebalanced return and the decomposed buyand-hold return. Liu and Strong [2008] demonstrate that rebalancing can lead to spurious statistical inference (the two methods produce a difference in returns of $8 \%$ p.a.), and document that rebalancing overstates the size and book-to-market effects, and understates the momentum effect. A more recent empirical study by Gray [2014] uses Australian equities to support the evidence documented in Liu and Strong [2008]. In particular, Gray [2014] shows that the constant weight approach produces significant biases into estimated returns, which, depending on the characteristics of stocks, can approach $1.5 \%$ per month.

As outlined above, the existing literature underlines the importance of investigating biases in portfolio mean returns as these can become significant, leading to incorrect inference and investment decisions. Surprisingly, however, the existing works seem to ignore biases that arise in portfolio's higher moments, such as the portfolio variances. Inspired by the work of Liu and Strong [2008] who document significance of the bias in portfolio mean returns, we investigate biases that arise in portfolio variances. We define the bias in portfolio variances as the difference between portfolio variance resulting from using the rebalancing strategy and the buy-and-hold approach.

Using large-scale portfolio simulation we confirm our conjecture that, similarly to the bias in portfolio mean returns, biases in portfolio variance exist and can become significant. We test the robustness of our results by constructing a large number of portfolios of randomly selected stocks from the S\&P 500 constituent list during the 2003-2011 period. We analyse how often our constructed portfolios differ in terms of estimated portfolio mean returns

\footnotetext{
${ }^{4}$ As a matter of fact, in 2009, Warren Buffett told PBS “I read a book, what is it, almost 60 years ago roughly, called The Intelligent Investor and I really learned all I needed to know about investing from that book, and in particular chapters 8 and 20... I haven't changed anything since". Chapter 8 of Benjamin Graham's The Intelligent Investor discusses the benefits of a buy-and-hold approach. It reads "...The true investor scarcely ever is forced to sell his shares, and at all other times he is free to disregard the current price quotation. He need pay attention to it and act upon it only to the extent that it suits his book, and no more. Thus the investor who permits himself to be stampeded or unduly worried by unjustified market declines in his holdings is perversely transforming his basic advantage into a basic disadvantage. That man would be better off if his stocks had no market quotation at all, for he would be spared the mental anguish caused him by other persons' mistakes of judgement." (Graham and Zweig, 2003, pp.106-107).
} 
and variances when the fixed weight rebalancing strategy is used instead of the buy-andhold approach. We show that the portfolio variance bias approaches an asymptotic value as the number of assets in the portfolios increases, indicating the systematic nature of the bias. We find that, compared to the buy-and-hold strategy, rebalancing led to a decrease in volatility of portfolios during 2003, 2005 and 2010, but caused a significant increase in volatility in the more turbulent 2008 and 2011, following the GFC and the European sovereign debt crisis. This is because maintaining equal portfolio weights would require an investor to adopt a buying "losers" and selling "winners" strategy, which would result in a portfolio with elevated volatility due to a large number of "losers" during bear markets and, subsequently, positive variance biases compared to a buy-and-hold portfolio.

Our results indicate that one should exercise caution when assuming multi-period rebalanced portfolio returns, as resulting biases can lead to spurious results when analysing investment strategies or testing asset pricing models. We add to the literature by challenging the equal weight rebalancing strategy that is widely adopted in the literature and demonstrate that continuous rebalancing will not lead to the optimal outcomes in periods of high volatility. The existence of portfolio variance biases during these periods have important implications not only when evaluating the risk of such portfolios, but also when assessing their performance by means of the coefficient of variation, the Sharpe ratio or the signal-to-noise ratio. In addition, we show that for individual investors, who in practice often employ buyand-hold strategy, the portfolio sizes required to achieve the most diversification benefits are understated.

We emphasise that the results presented in this paper condone neither of the considered strategies. We are not providing a uniform recommendation to market participants on which strategy to adopt. We do find, however, that outcomes from rebalancing strategies appear to be favourable during good economic conditions, but display larger portfolio volatility during economic downturns compared to outcomes of buy-and-hold portfolios. We point out that investors should be consistent when considering decomposed portfolio returns. For a buyand-hold investor, it would be misleading to calculate portfolio returns using fixed weights and, thus, incorrectly assume periodic rebalancing. For an investor pursuing a fixed weight rebalancing strategy, a constant weight applied to portfolio holdings at the beginning of every period is the only correct approach. Portfolio returns constructed based on the wrong underlying portfolio strategy may lead to biases in portfolio mean returns and portfolio variances. In other words, imposing fixed initial weights when calculating decomposed buy-and-hold portfolio returns may result in biased estimates and incorrect performance metrics.

To summarise, our motivation to compare both, the rebalancing and the buy-and-hold investment strategies, and the resulting portfolio risk, draws on the conclusions from previous academic literature, which suggests that a simple averaging approach introduces significant estimation error. In fact, the estimated returns fail to capture correctly the wealth effects for an investor holding the portfolio, and leads to incorrect statistical inferences in relation 
to investment strategies. The issues and the results discussed in this paper emphasise the importance of examining portfolio characteristics carefully, and deciding on the investment strategy, knowing possible consequences. This paper will be of interest to researchers testing asset pricing models and practitioners evaluating the performance of investment strategies.

The remainder of the paper is organised as follows. In Section 2 we derive variance bias in multi-period portfolio returns by contrasting the buy-and-hold and the rebalancing methods. In Section 3 we form buy-and-hold and rebalancing portfolios by selecting stocks randomly from the S\&P 500 constituent list and analyse the biases empirically. Section 4 contrasts optimal portfolio sizes of well-diversified portfolios under the two portfolio construction methods. In Section 5 we draw conclusions and provide final remarks.

\section{Derivations}

This section derives biases in portfolio mean returns and portfolio variances. We define bias as the difference between portfolio risk estimates constructed using rebalanced returns and the decomposed buy-and-hold returns. The constructed biases will be analysed in Section 3 when comparing the performance of investors' portfolios constructed using the equally weighted approach and the buy-and-hold strategy.

We begin by focusing on a distinction between decomposed buy-and-hold portfolio returns and rebalanced portfolio returns, assuming that rebalancing is performed every period according to the data sampling frequency. ${ }^{5}$ Denoting $P_{i, \tau}$ the price of the $i$ th stock $(i=1, \ldots, N)$ in a holding period $\tau=1, \ldots, T$ where $T$ is the end of the investment horizon, we define individual stock $i$ 's simple return for the period $\tau$ by $r_{i, \tau}=\frac{P_{i, \tau}-P_{i, \tau-1}}{P_{i, \tau-1}}$. ${ }^{6}$ We assume that the investor holds a portfolio of $N$ stocks. When constructing our rebalanced portfolios we adopt the most popular approach - an equally weighted portfolio, choosing the weight of stock $i$ to be $w_{i}=1 / N$ at the beginning of each holding period $\tau$. We note, however, that the results derived below can be generalised to arbitrary weights $w_{i}$ with $\sum_{i=1}^{N} w_{i}=1$. $^{7}$

For the rebalanced portfolios, returns in each holding period $\tau$ can be computed as an average of the individual stock returns in that period, that is,

$$
r_{r e b, \tau}=\frac{1}{N} \sum_{i=1}^{N} r_{i, \tau}
$$

\footnotetext{
${ }^{5}$ The portfolio is rebalanced every month when using monthly data, every week when using weekly data, and every day when using daily data, etc. The holding period for the buy-and-hold portfolio is set to one year or the entire period, depending on the application.

${ }^{6}$ Note that we do not adjust returns for dividends. Although relying on dividend adjusted returns is common when monthly, weekly, or even daily data is employed, in analyses of high-frequency data (in our case, 5-min returns) there has been no occurrences in the extant literature. Furthermore, since the object of our investigation is variance (and not returns), and dividend adjustment is performed by multiplying historical prices prior to the dividend by the adjustment factor, this proportional quarterly correction poses no issues for the variance bias results we obtain.

${ }^{7}$ The $1 / N$ strategy is often used in practice and its out-performance across a wide range of different asset allocation strategies is well documented in the literature (e.g., DeMiguel et al., 2009).
} 
The rebalancing method is inaccurate in reflecting investors' wealth over a multi-period holding horizon, unless the portfolio is rebalanced back to the initial weights at the beginning of each period $\tau$. This, however, appears unrealistic from an investor's perspective, since revisions of portfolio weights are unlikely to occur at regular intervals, especially when taking into account the prohibitive transaction costs associated with frequent periodic rebalancing. In practice, new information flow will determine when revisions of weights should take place if at all. ${ }^{8}$

For the buy-and-hold portfolio approach, which is a standard and accurate method for measuring the investment performance of the buy-and-hold investor, the return in the first period, $\tau=1$, can be computed as

$$
r_{b h, 1}=\frac{1}{N} \sum_{i=1}^{N} r_{i, 1}
$$

The returns in any subsequent period, $\tau=2, \ldots, T$, are given by

$$
r_{b h, \tau}=\frac{1}{\sum_{j=1}^{N} \prod_{t=1}^{\tau-1}\left(1+r_{j, t}\right)} \sum_{i=1}^{N} \prod_{t=1}^{\tau-1}\left(1+r_{i, t}\right) r_{i, \tau} .
$$

Thus, in the first period the buy-and-hold portfolio return corresponds to the average of the individual stock returns in this period, and is equivalent to the return on the rebalanced portfolio. For periods $\tau=2, \ldots, T$, the buy-and-hold portfolio returns are computed as the weighted average of period $\tau$ stock returns with weights determined by the performance over previous periods. Under the assumption of no auto- and cross-autocorrelation in individual stock returns, the returns for rebalanced portfolios in any two periods are independent, whereas for the buy-and-hold portfolios the returns are dependent in any two periods. ${ }^{9}$

\subsection{Bias in portfolio mean returns}

We denote the average return on the rebalanced portfolio by

$$
\bar{r}_{\tau}=\frac{1}{N} \sum_{i=1}^{N} r_{i, \tau}
$$

and thus, the expected return of the rebalanced portfolio is given by

$$
E\left(r_{r e b, \tau}\right)=E\left[\frac{1}{N} \sum_{i=1}^{N} r_{i, \tau}\right]=E\left[\bar{r}_{\tau}\right] .
$$

\footnotetext{
${ }^{8}$ Graham and Zweig [2003] argue that investors are better off adopting a buy-and-hold approach.

${ }^{9}$ For example, the returns in the two periods of a buy-and-hold portfolio are dependent. Consider a value weighted two-stock portfolio consisting of stocks $A$ and $B$. In the the first period, portfolio return is calculated as $R_{p, 1}=a_{1} * R_{A, 1}+b_{1} * R_{B, 1}$. Then, portfolio return in the second period is calculated as $R_{p, 2}=\left(a_{1}\left(1+R_{A, 1}\right) *\right.$ $\left.R_{A, 2}+a_{2}\left(1+R_{B, 1}\right) * R_{B, 2}\right) /\left(a_{1}\left(1+R_{A, 1}\right)+a_{2}\left(1+R_{B, 1}\right)\right)$ and is clearly dependant on returns in the first period.
} 
First, we derive the return bias for $\tau=2$, and then generalise it to an arbitrary $\tau .{ }^{10}$ We use the approximation $1 /\left(1+\bar{r}_{\tau}\right) \approx 1-\bar{r}_{\tau}$, ignoring higher order terms in the Taylor series expansion. The bias between the expected return of the rebalanced and the buy-and-hold portfolios is given by

$$
\operatorname{Bias}_{2}^{E}=E\left(r_{r e b, 2}\right)-E\left(r_{b h, 2}\right),
$$

and using Eq. (5) and Eq. (3) for $\tau=2$, we can write

$$
\operatorname{Bias}_{2}^{E}=E\left[\bar{r}_{1} \bar{r}_{2}\right]-\frac{1}{N} \sum_{i=1}^{N} E\left[\left(1-\bar{r}_{1}\right) r_{i, 1} r_{i, 2}\right]
$$

The result in Eq. (7) has been documented in Liu and Strong [2008], its derivations appear in Appendix A to make this study self-contained.

Assuming that $\bar{r}_{1}$ is uncorrelated with individual returns $r_{i, 1}$ and $r_{i, 2}$, as proposed in Liu and Strong [2008], Eq. (7) can further be decomposed as

$$
\begin{aligned}
\operatorname{Bias}_{2}^{E}= & E\left(\bar{r}_{1}\right) E\left(\bar{r}_{2}\right)+\underbrace{\operatorname{Cov}\left(\bar{r}_{1,} \bar{r}_{2}\right)}_{>0}-\underbrace{E\left(1-\bar{r}_{1}\right)}_{>0} \frac{1}{N} \sum_{i=1}^{N} E\left(r_{i, 1}\right) E\left(r_{i, 2}\right) \\
& +\underbrace{[-\underbrace{E\left(1-\bar{r}_{1}\right)}_{>0} \frac{1}{N} \sum_{i=1}^{N} \underbrace{\operatorname{Cov}\left(r_{i, 1}, r_{i, 2}\right)}_{<0}]}_{>0} .
\end{aligned}
$$

Eq. (8) indicates that even if returns are independent, the return bias is non-zero. The bias depends on the expected average portfolio return of the rebalanced portfolio, expected individual stock returns, the autocovariance of the portfolio returns and autocovariances of individual stock returns. Following the empirical evidence documented in Lo and Mackinlay [1990] and Mech [1993], portfolio returns are positively autocorrelated, that is, $\operatorname{Cov}\left(\bar{r}_{1}, \bar{r}_{2}\right)>0$ for the rebalanced portfolio, contributing positively to a bias. ${ }^{11}$ Conversely, individual returns are negatively autocorrelated, that is, $\operatorname{Cov}\left(r_{i, 1}, r_{i, 2}\right)<0$, see Fisher [1966], Roll [1984], Lo and Mackinlay [1990], Jegadeesh and Titman [1995]. ${ }^{12}$ This negative autocorrelation is more pronounced in small and low-price stocks, see Lo and Mackinlay [1990]. Hence, in portfolios comprised of small and low-price stocks, one would expect to observe a positive bias. ${ }^{13}$ On the other hand, Kaul and Nimalendran [1990] document positive autocorrelation

\footnotetext{
${ }^{10}$ We note that there is no bias if the holding period corresponds to a single period $(\tau=1)$. However, one would not consider an investment strategy based on a single period as it is unattractive due to transaction costs; or simply not adequate for constructing a sufficient sample of decomposed portfolio returns for testing asset pricing models.

${ }^{11}$ In fact, transaction costs cause the portfolio return autocorrelation by delaying price adjustment.

${ }^{12}$ The negative autocorrelation in individual returns is caused by nonsynchronous trading (Fisher, 1966), transaction costs and bid-ask spreads (Roll, 1984, Jegadeesh and Titman, 1995).

${ }^{13}$ For instance, Liu [2006] documents high correlation between the returns of infrequently traded stocks and size,
} 
between stock returns once the bid-ask spread is extracted; which may lead to negative bias in portfolios comprised of large and high-price stocks.

Using Eq. (3) and Eq. (5), we can express the bias in portfolio mean returns for $\tau=2, \ldots, T$ as

$$
\begin{aligned}
\operatorname{Bias}_{\tau}^{E} & =E\left(r_{r e b, \tau}\right)-E\left(r_{b h, \tau}\right) \\
& =\sum_{i=1}^{N}\left[\frac{1}{N} E\left(r_{i, \tau}\right)-E\left(\frac{1}{\sum_{j=1}^{N} \prod_{t=1}^{\tau-1}\left(1+r_{j, t}\right)} \sum_{i=1}^{N} \prod_{t=1}^{\tau-1}\left(1+r_{i, t}\right) r_{i, \tau}\right)\right] .
\end{aligned}
$$

Generalising the discussion above to an arbitrary $\tau$, we concur that positive bias in portfolio mean returns is most likely to occur in small and low-price stock portfolios, and negative bias is expected in large and high-price stock portfolios. Liu and Strong [2008] note that negative bias can arise when expected stock returns are constant over time but vary cross-sectionally, that is, when high (low) expected returns are associated with higher (lower) expected weights in the buy-and-hold portfolios (second term of Eq. (9)). Rebalancing reverses this effect (first term of Eq. (9)).

The two approximations employed by Liu and Strong [2008] to arrive at a closed form solution in Eq. (7) are restrictive. It is well- known that the distribution of individual securities is negatively skewed. As a result, this approximation may not be valid. In our empirical analysis we avoid using the closed form solution and rely on real data with no assumptions on return distributions. ${ }^{14}$

\subsection{Bias in portfolio variance}

Similar to the computation of the bias in portfolio mean returns, we derive bias in portfolio variance for $\tau=2$, and generalise it to an arbitrary $\tau$. The variance bias between the rebalanced and the buy-and-hold portfolio is given by

$$
\operatorname{Bias}_{2}^{V}=\operatorname{Var}\left(r_{r e b, 2}\right)-\operatorname{Var}\left(r_{b h, 2}\right),
$$

where the variance of the rebalanced portfolio is determined by

$$
\operatorname{Var}\left(r_{r e b, 2}\right)=\operatorname{Var}\left[\bar{r}_{2}\right]=E\left[\bar{r}_{2}^{2}\right]-E\left[\bar{r}_{2}\right]^{2},
$$

and the variance of the buy-and-hold portfolio can be written (see Appendix A for details) as

as well as the bid-ask spread; and Branch and Freed [1977], Conrad and Kaul [1993] find a negative relationship between price and the bid-ask spread.

${ }^{14}$ The following result employs the second order Taylor expansion around zero: $1 /(1+r) \approx 1-r+r^{2}$ for $r \rightarrow 0$. Using daily return data for the S\&P500 constituents, we estimate, on average, less than $0.01 \%$ difference between approximations using the first vs the second order Taylor series. 


$$
\operatorname{Var}\left(r_{b h, 2}\right)=\operatorname{Var}\left[\left(1-\bar{r}_{1}\right)\left(\bar{r}_{2}+\frac{1}{N} \sum_{i=1}^{N} r_{i, 1} r_{i, 2}\right)\right] .
$$

Continuing with the assumption that portfolio returns $\bar{r}_{1}$ and $\bar{r}_{2}$ are uncorrelated with individual stock returns, $r_{i, 1}$ and $r_{i, 2}$, and using the approximation $1 /\left(1+\bar{r}_{\tau}\right) \approx 1-\bar{r}_{\tau}$ as before, ${ }^{15}$ Bias $_{2}^{V}$ for the variance reduces to

$$
\begin{aligned}
\operatorname{Bias}_{2}^{V} & =\operatorname{Var}\left(r_{r e b, 2}\right)-\operatorname{Var}\left(r_{b h, 2}\right) \\
& =2 \operatorname{Cov}\left(\bar{r}_{2}, \bar{r}_{1} \bar{r}_{2}\right)-\underbrace{\operatorname{Var}\left(\bar{r}_{1} \bar{r}_{2}\right)}_{>0}-\underbrace{\frac{1}{N^{2}} \operatorname{Var}\left(\sum_{i=1}^{N} r_{i, 1} r_{i, 2}\right)}_{>0}-\underbrace{\frac{1}{N^{2}} \operatorname{Var}\left(\bar{r}_{1} \sum_{i=1}^{N} r_{i, 1} r_{i, 2}\right)}_{>0} .
\end{aligned}
$$

From Eq. (13) we observe that the bias in portfolio variance is not zero; it depends on the autocovariance of portfolio returns, the autocovariance of individual returns, as well as the variance of the sum of product of individual and portfolio returns. Similarly to the bias in portfolio mean return, the bias in portfolio variance can take either positive or negative values, depending on the time-series properties of portfolio returns and individual stock returns. Using the same argument as above, portfolio returns are more likely to be positively autocorrelated, that is $\operatorname{Cov}\left(\bar{r}_{1}, \bar{r}_{2}\right)>0$, for the rebalanced portfolio (see, for example, Lo and Mackinlay, 1990, Mech, 1993). Hence, positive autocovariance in portfolio returns will contribute to a positive bias in variance.

Eq. (13) can be generalised for $\tau=2, \ldots, T$ as follows:

$$
\begin{aligned}
\operatorname{Bias}_{\tau}^{V} & =\operatorname{Var}\left(r_{r e b, \tau}\right)-\operatorname{Var}\left(r_{b h, \tau}\right) \\
& =\operatorname{Var}\left(\bar{r}_{\tau}\right)-\operatorname{Var}\left[\frac{1}{\sum_{j=1}^{N} \prod_{t=1}^{\tau-1}\left(1+r_{j, t}\right)} \sum_{i=1}^{N} \prod_{t=1}^{\tau-1}\left(1+r_{i, t}\right) r_{i, \tau}\right] .
\end{aligned}
$$

Relative to a buy-and-hold approach, a negative bias indicates that a rebalancing strategy underestimates the average portfolio return or variance, while a positive bias shows that a rebalancing strategy overstates these estimates.

\section{Empirical analysis}

In this section we put our theoretical results derived in Section 2 to the test. We first discuss data used for construction of rebalanced and decomposed buy-and-hold portfolio

\footnotetext{
${ }^{15}$ We tested the simplifying assumption, $1 /\left(1+\bar{r}_{\tau}\right) \approx 1-\bar{r}_{\tau}$, by investigating the difference between empirical portfolio return and variance biases in Eqs. (6) and (10), respectively, and biases calculated based on the decomposed terms under simplifying assumption in Eqs. (8) and (13). These results show that the difference between the two bias estimates is negligible.
} 
returns, followed by the estimation methodology, results and implications for portfolio construction and investment decisions.

\subsection{Data}

We construct equally weighted rebalanced and buy-and-hold portfolios of various sizes from S\&P 500 constituents over a nine-year sample period from January 2, 2003 to December 30, 2011. We let the number of stocks in each portfolio vary between 1 and 80, and select stocks randomly without replacement. The period under consideration includes the global financial crisis (GFC) associated with the bankruptcy of Lehman Brothers in September 2008 and the subsequent period of turmoil in the U.S. and international financial markets. The underlying data are 5 minute, daily, weekly and monthly observations on prices for 501 stocks drawn from the constituent list of the S\&P 500 index during the sample period, obtained from SIRCA Thompson Reuters Tick History. This data set was constructed by Dungey et al. [2012] and does not contain all the stocks listed in the S\&P 500 index, but has drawn from that population to select those with sufficient coverage and data availability for high frequency time series analysis. The original dataset of over 900 stocks was taken from the 0\#.SPX mnemonic provided by SIRCA. This included several stocks that were traded OTC and on alternative exchanges. The stocks that changed the currency in which they were traded during the period under consideration were excluded from the analysis. We adjusted the dataset for changes in RIC codes ${ }^{16}$ resulted from mergers and acquisitions, stock splits and trading halts. We removed stocks with insufficient number of observations. We force the inclusion of Lehman Brothers until their bankruptcy in September 2008, but drop Fannie Mae and Freddie Mac from the analysis. The data handling process is documented in the web-appendix to Dungey et al. [2012]. The final data set contains 501 individual stocks. Our estimation methods are summarised in the next subsection and detailed in Appendix B. The full list of stocks including Reuters Identification Codes (RICs) is provided in the supplementary online appendix.

\subsection{Estimation method and results}

We allow for the diversification effect in portfolios, that is, the relationship between the decreasing risk in portfolios when the number of securities in these portfolios increases. ${ }^{17}$ Figure 2 represents the variance bias in portfolios by year (2003-2011). ${ }^{18}$ To calculate biases, for each simulated portfolio, we retain the same draw of stocks from the S\&P 500 constituents list when contrasting rebalanced and buy-and-hold approaches. ${ }^{19}$ The number of stocks,

\footnotetext{
${ }^{16}$ A Reuters instrument code, or RIC, is a ticker-like code used by Thomson Reuters to identify financial instruments and indices.

${ }^{17}$ We note that one can obtain most of the benefits of diversification by holding a relatively small number of stocks; see, e.g., Elton and Gruber [1977].

${ }^{18}$ In the finance literature, measuring risk is more contentious than measuring return. With different sampling frequencies, our risk measures, even when annualised, may differ. To help in our comparison of biases in portfolio variance across different data sampling frequencies, we find it practical to focus on relative measures for presentation purposes, and define bias in portfolio variance in our empirical section as Bias $V / \operatorname{Var}\left(r_{b h}\right)$.

${ }^{19}$ Our results demonstrate significant biases when considering a sample of large stocks from the S\&P 500 index. As documented in Liu and Strong [2008, p.2245], one would expect to observe even more significant results when considering low-price, small, and loser stocks.
} 


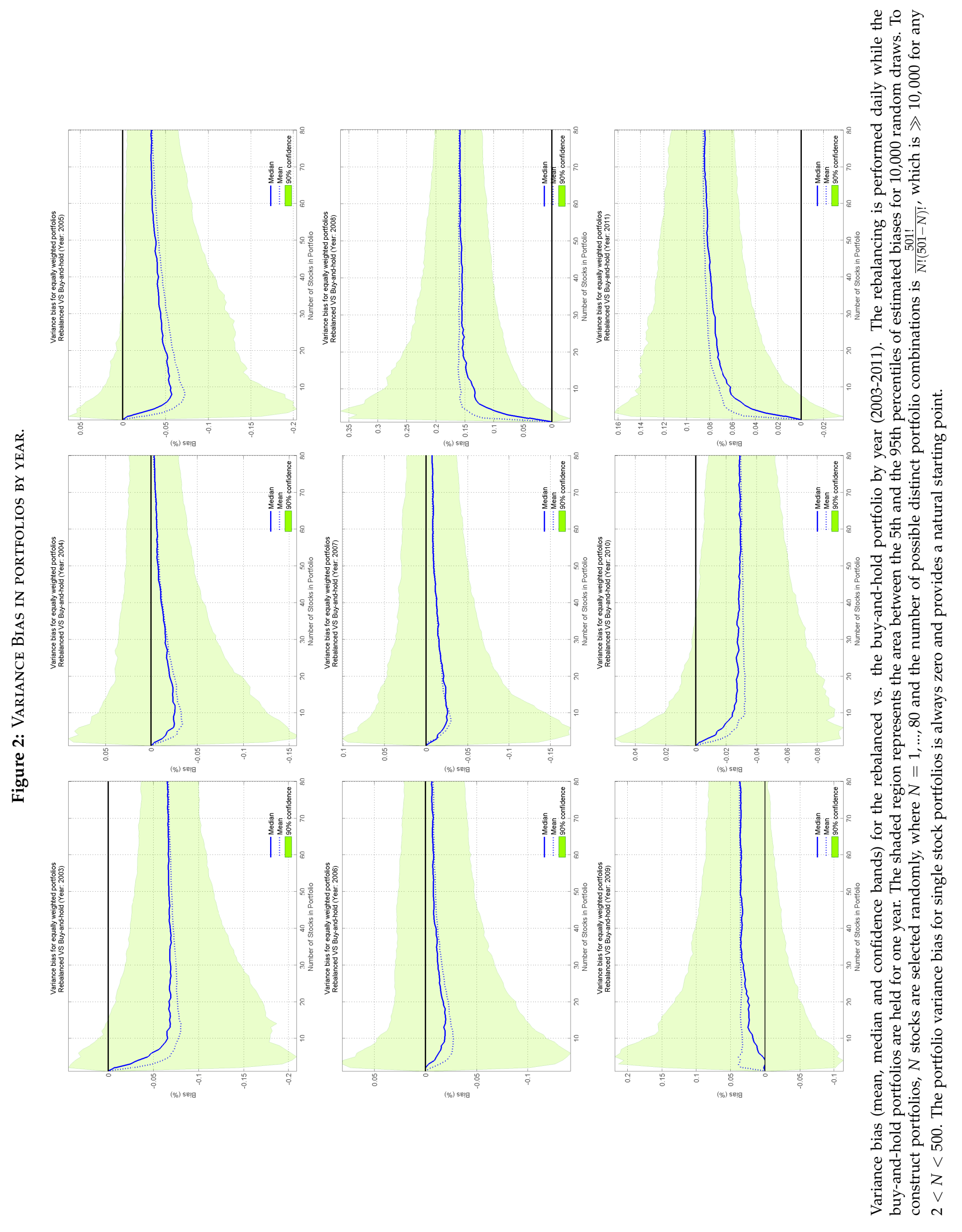


Figure 3: BIAS IN PORTFOLIOS AT DIFFERENT FREQUENCIES.
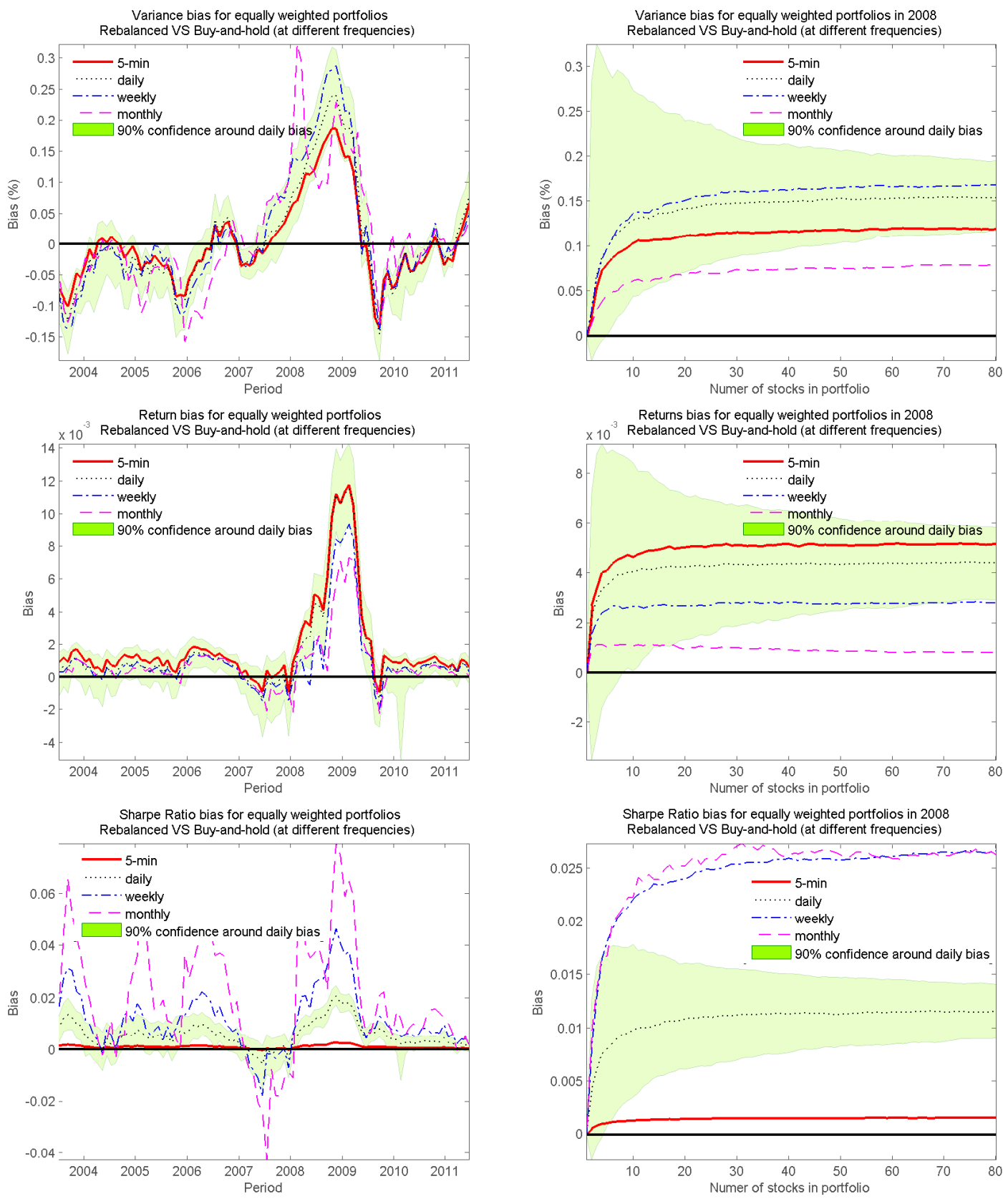

Variance bias (top panel), average return bias (middle panel) and signal-to-noise ratio bias (bottom panel) across time (left panels) and for the selected year 2008 (right panels). All quantities are constructed based on returns of randomly selected portfolios of 50 assets using the past one year of data. At the end of each month in the period from 2003 to 2011 we obtain portfolio bias estimates using one year of past data (panels on the left). Using 5 -minute, daily, weekly and monthly sampling frequencies, we estimate variance biases for 2008 across randomly selected portfolios of sizes $N=1, \ldots, 80$ stocks (panels on the right). The rebalancing is performed depending on the frequency being analysed while the buy-and-hold portfolios are held for one year either in a rolling window (left panels) or a single exemplar year (right panels). The shaded region represents the area between the 5 th and the 95th percentile of estimated daily biases for 10,000 random draws. To construct portfolios, $N$ stocks are selected randomly, where $\frac{501 !}{N !(501-N) !} \gg 10,000$. We use the same dataset but sample at different frequencies. We keep the same sample of assets in each simulated portfolio across estimations for different frequencies. Overnight returns for the 5-minute data have been included.

\section{$N=1, \ldots, 80$, is shown on the $\mathrm{x}$-axis. ${ }^{20}$ Stocks in the simulated portfolios are chosen randomly}

\footnotetext{
${ }^{20}$ The portfolio variance bias for a single stock portfolio is always zero and provides a natural starting point in the Figure.
} 
without replacements with the number of stocks in portfolios varying from 1 to $80 .{ }^{21}$ We perform 10,000 random draws and compute the median variance bias (blue solid line in Figure 2), the mean variance bias (blue dotted line) and the $90 \%$ confidence band (shaded region between the 5th and the 95th percentile of estimated biases based on 10,000 draws for each portfolio size). We observe that the sign of the variance bias depends on the year under consideration. For example, during the turbulent 2008 associated with the start of the GFC, variance bias is positive and significant, which shows that the rebalancing approach has exacerbated the estimates of variance. This is because maintaining equal portfolio weights will require an investor to adopt the buying "losers" and selling "winners" strategy, which will result in a portfolio with increased volatility (due to a large number of "losers" during the GFC) and, subsequently, positive variance biases compared to a buy-and-hold portfolio. This is in contrast to the results obtained in calm periods, e.g., 2003-2007, when the variance bias is significant and negative. The results indicate that rebalancing during bad economic times leads to elevation of portfolio volatility and thus, might not be optimal in bear markets. In addition, we observe that variance biases, in most cases, approach an asymptotic value for portfolios in excess of 50 assets depending on the year considered, which points out a systematic nature of the biases.

For brevity we choose to analyse well-diversified portfolios comprised of 50 stocks, where stocks are selected randomly without replacement. The number of random draws remains 10,000. ${ }^{22}$ Every month, in the period from 2003 to 2011, we trace biases in portfolio mean returns, portfolio variances and signal-to-noise ratios ${ }^{23}$ using one year of past data. These are shown in the left panels of Figure 3 for the variance bias (top left), mean return bias (middle left) and signal-to-noise ratio bias (bottom left). Although our focus in this section is on the analysis of daily returns, we apply 5-minute, weekly and monthly sampling frequencies as robustness checks when estimating variance biases. ${ }^{24}$ We use the same dataset and the same random selection of assets in each simulated portfolio but sample prices at different frequencies to reconstruct multi-period returns. Overnight returns for 5-minute data have been included to ensure that the terminal wealth of a buy-and-hold investor is accounted for correctly. ${ }^{25}$ Panels on the right (Figure 3) show biases for $2008^{26}$ across randomly selected

\footnotetext{
${ }^{21}$ Alexeev and Tapon [2014] show that 80 stocks are sufficient to get most of the diversification benefits even for conservative investors. Alexeev and Dungey [2015] reconfirm this result using high-frequency data.

${ }^{22}$ The total number of possible combinations of 50 stocks out of 501 is $\frac{501 !}{50 !(501-50) !}=2.57 \times 10^{69}$.

${ }^{23}$ The bias in the signal-to-noise ratio will be similar to the bias in the Sharpe ratio if the risk free rate remains constant throughout the entire holding period. For small infrequent changes in the risk free rate, the two biases will be approximately equal. The difference between the signal-to-noise and the Sharpe ratio corresponds to $\triangle r_{f}\left(\frac{\sigma_{b h}-\sigma_{r e b}}{\sigma_{b h} \sigma_{r e b}}\right)$.

${ }^{24}$ We showed that the bias in portfolio variance is influenced by the intertemporal dependencies in returns. Much of the autocovariance in individual stock returns can be attributed to the bid-ask bounce and the shortterm autocovariance in portfolio returns to non-synchronous trading. Increasing the sampling frequency of our data will make these effects more pronounced.

${ }^{25}$ We also estimate the bias in portfolio variance when overnight returns are excluded and observe that the sign and significance of the portfolio variance biases in every period remain the same.

${ }^{26}$ This year corresponds to the beginning of the GFC, and was selected as a prominent example of high volatility in the financial markets.
} 
portfolios of size $N=1, \ldots, 80$ stocks. The shaded region represents the $90 \%$ confidence interval around daily biases. As expected, the higher the frequency of the data, and thus, the frequency of rebalancing to maintain equal weights in the portfolio, the larger the bias in returns (middle right panel). Confirming the results reported in Figure 2, we observe from the left panel of Figure 3 that for portfolios of 50 assets, significant negative biases occur during 2003, 2005 and 2010. This indicates that rebalancing of portfolios in these years leads to a lower variance than the buy-and-hold approach, and thus, indicates that the rebalancing strategy underestimates portfolio variance. Significantly positive biases, occurring in the more turbulent 2008 and 2011, indicate that the rebalancing strategy overshoots the buy-and-hold strategy. This confirms our previous results that the rebalancing appears to be a favourable strategy during good economic conditions, but results in larger portfolio volatility during economic downturns.

In Table 1 we present a summary of the results for equally weighted rebalanced and buyand-hold portfolios, obtained using daily data and 10,000 randomly constructed portfolios of 50 stocks. We assume that from the first trading day of the year the investor either follows a rebalancing strategy and calculates portfolio returns using Eq. (1), or adheres to a buy-andhold strategy using Eq. (3). For each given year we estimate portfolio mean returns (columns 1 and 4), standard deviations (columns 2 and 5) and signal-to-noise ratios ${ }^{27}$ (columns 3 and 6 ) based on daily returns within that year. The results are reported in annualised terms. ${ }^{28}$ For the bias results in columns (7) through (9), "*" denotes significance at $10 \%$ significance level, that is, when the range from the 5th percentile to the 95th percentile of estimated biases in portfolio statistics for a given year does not contain zero. We emphasise that the bias statistics are computed based on matched pairs of rebalanced and buy-and-hold portfolio returns, i.e., for the same draw of stocks in the same period. We compute biases at the end of a year for each of the 10,000 portfolios, and then average them across these portfolios. We notice that portfolio mean returns in 2006, and especially in 2008-2009, were overstated by the rebalancing approach. This overstatement of portfolio returns have been observed in at least $90 \%$ of the 10,000 randomly constructed portfolios. On the other hand, the variance has been significantly understated in 2003, 2005, and 2010. The largest bias in portfolio variance has occurred in 2008, with another significant exaggeration in 2011. This confirms our previous results from Figure 2 and Figure 3. The overstatement of the signal-to-noise ratio by the rebalancing strategy occurred in 2003, 2006, 2008 and 2009. Table 2 reports the ten largest positive (negative) biases in portfolio mean returns and portfolio variances in panel A (panel B). We observe that the largest significant biases in portfolio mean returns occur during the most turbulent 2008-2009, confirming previous results. The results for the largest significant biases in portfolio variance are mixed; however 6 out of 9 significant biases occur

\footnotetext{
${ }^{27}$ We avoid the sample size bias in the signal-to-noise ratio discussed in Miller and Gehr [1978] since the number of observations is the same for both the buy-and-hold and the rebalanced portfolios in each simulation.

${ }^{28}$ Daily estimates have been annualised using a factor of 250 for mean returns, and $\sqrt{250}$ for standard deviation and signal-to-noise ratio.
} 


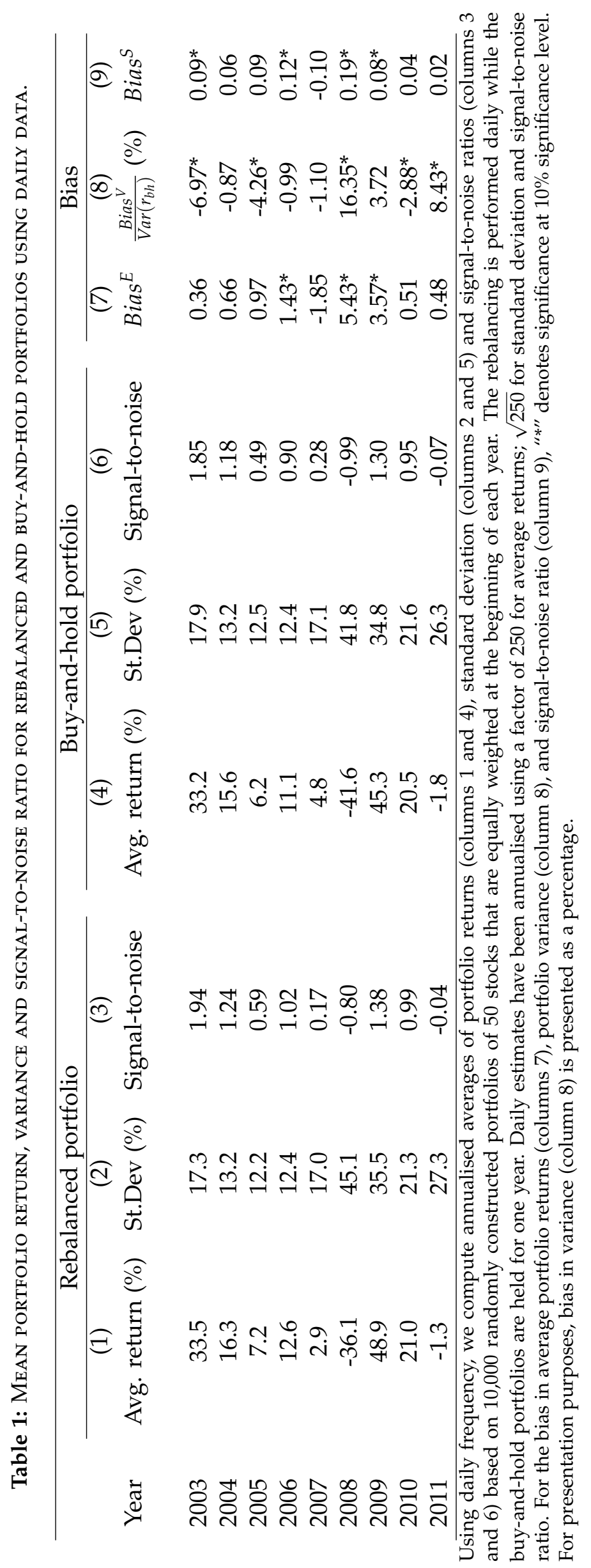


Figure 4: Bias Decomposition.
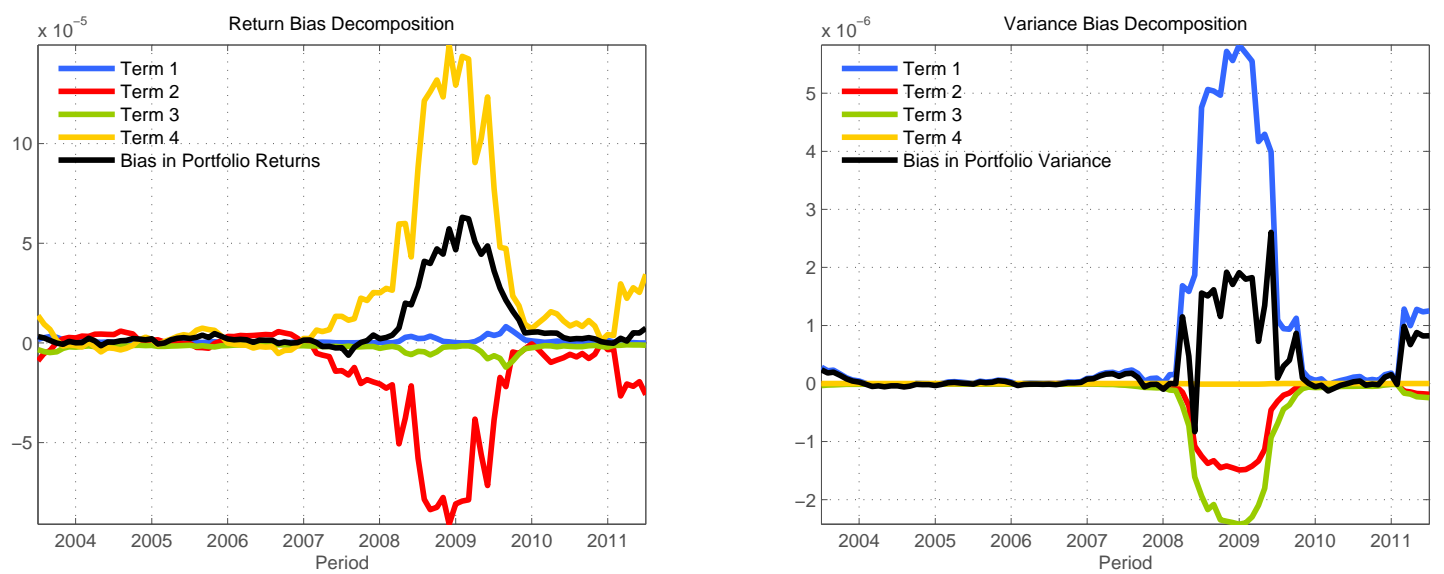

Return bias decomposition Bias ${ }_{2}^{E}$ derived in Eq.

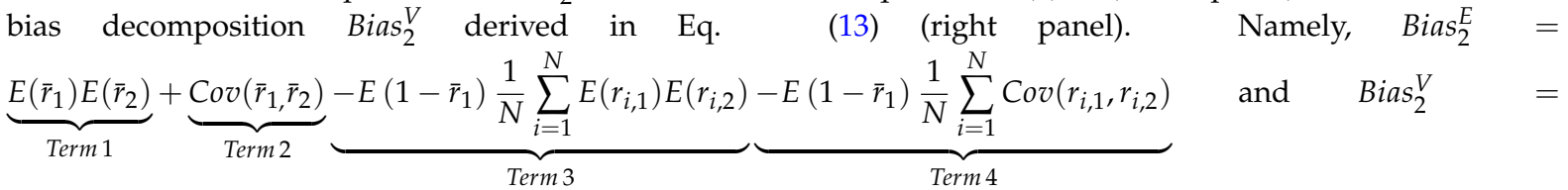

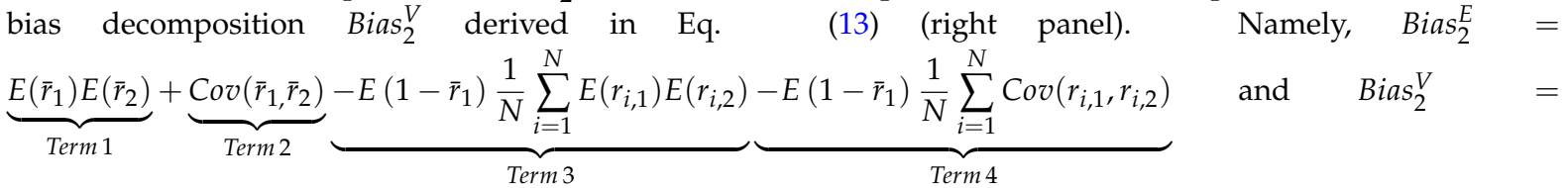

(8) (left panel) and variance

$2 \underbrace{\operatorname{Cov}\left(\bar{r}_{2}, \bar{r}_{1} \bar{r}_{2}\right)}_{\text {Term } 1} \underbrace{-\operatorname{Var}\left(\bar{r}_{1} \bar{r}_{2}\right)}_{\operatorname{Term} 2} \underbrace{-\frac{1}{N^{2}} \operatorname{Var}\left(\sum_{i=1}^{N} r_{i, 1} r_{i, 2}\right)}_{\text {Term } 3} \underbrace{-\frac{1}{N^{2}} \operatorname{Var}\left(\bar{r}_{1} \sum_{i=1}^{N} r_{i, 1} r_{i, 2}\right)}_{\text {Term } 4}$. Portfolios are constructed from randomly selected 50 assets. At the end of each month, in the period from 2003 to 2011, the bias estimates and the decomposed terms were obtained using one year of past data. Thus, the rebalancing is performed daily while the buy-and-hold portfolios are held for one year. Decomposed terms and biases are the averages of 10,000 randomly drawn portfolios each with 50 assets.

between November 2007 and August 2011. This period corresponds to the turbulent period of the financial crisis, followed by the global recession. We confirm previous results that the rebalancing method exacerbates expected returns and variances of buy-and-hold portfolios during that period. The results for the lowest biases indicate that none of the return biases are significant at the $90 \%$ level; however all the portfolio variance biases are significant, with the largest significant biases occurring in 2009. Our results indicate that researchers and portfolio managers may mistakenly measure portfolio performance when relying only on biases for the portfolio mean returns while ignoring second moments. This is especially pertinent for the situation at hand: although biases in portfolio mean returns appear insignificant due to increased volatility, biases in the variance of portfolios are significant for all years under consideration. Liu and Strong [2008] and Canina et al. [1998] discuss common time-series characteristics of both the portfolio and individual stocks returns and the implication that these characteristics may exhibit on the portfolio return bias. However, Canina et al. [1998] do not derive the portfolio mean return bias but instead use regression analysis to explain the bias using a set of time-series characteristics of the underlying portfolios and stocks. They calculate the cross-sectional average autocorrelations of each stock, the autocorrelations for the equally weighted rebalanced portfolio, and the cross-sectional variance of the average returns. Lo and Mackinlay [1990] document that average daily autocorrelations in returns are mostly negative. The empirical literature shows that individual stock returns are negatively 
Table 2: 20 LARGEST BIASES.

\begin{tabular}{|c|c|c|c|c|c|c|c|}
\hline Rank & Year & Month & Bias $^{E}$ & Rank & Year & Month & $\frac{\text { Bias }^{V}}{\operatorname{Var}\left(r_{b h}\right)}(\%)$ \\
\hline \multicolumn{8}{|c|}{ Panel A: Months with highest bias } \\
\hline 1 & 2008 & October & $15.84^{*}$ & 1 & 2008 & November & $8.51^{*}$ \\
\hline 2 & 2009 & March & $13.17^{*}$ & 2 & 2008 & October & $7.51^{*}$ \\
\hline 3 & 2008 & November & $11.36^{*}$ & 3 & 2009 & January & $4.47^{*}$ \\
\hline 4 & 2008 & December & 6.31 & 4 & 2006 & July & $4.40^{*}$ \\
\hline 5 & 2008 & September & 4.29 & 5 & 2009 & February & $4.20^{*}$ \\
\hline 6 & 2008 & July & $3.49^{*}$ & 6 & 2004 & July & $4.01^{*}$ \\
\hline 7 & 2009 & February & 3.27 & 7 & 2008 & September & 3.80 \\
\hline 8 & 2009 & May & 3.06 & 8 & 2006 & June & $3.32^{*}$ \\
\hline 9 & 2008 & January & 3.02 & 9 & 2011 & August & $3.15^{*}$ \\
\hline 10 & 2009 & January & 2.91 & 10 & 2007 & November & $2.93^{*}$ \\
\hline \multicolumn{8}{|c|}{ Panel B: Months with lowest bias } \\
\hline 108 & 2009 & April & -4.47 & 108 & 2009 & April & $-10.53^{*}$ \\
\hline 107 & 2008 & June & -2.63 & 107 & 2009 & May & $-5.53^{*}$ \\
\hline 106 & 2009 & August & -2.36 & 106 & 2009 & August & $-4.91^{*}$ \\
\hline 105 & 2011 & September & -1.68 & 105 & 2004 & January & $-3.57^{*}$ \\
\hline 104 & 2006 & January & -0.89 & 104 & 2008 & August & $-3.26^{*}$ \\
\hline 103 & 2003 & April & -0.81 & 103 & 2003 & August & $-3.16^{*}$ \\
\hline 102 & 2003 & May & -0.79 & 102 & 2003 & October & $-2.83^{*}$ \\
\hline 101 & 2009 & December & -0.75 & 101 & 2010 & April & $-2.34^{*}$ \\
\hline 100 & 2007 & December & -0.74 & 100 & 2003 & July & $-2.29^{*}$ \\
\hline 99 & 2004 & April & -0.70 & 99 & 2011 & October & $-2.29^{*}$ \\
\hline
\end{tabular}

The largest positive (negative) biases in portfolio returns and portfolio variances are reported in panel A (panel B). At the end of each month in the period from 2003 to 2011 we obtain portfolio bias estimates using one month of past data. The rebalancing is performed daily while the buy-and-hold portfolios are held for one month. We observe that the largest significant biases in portfolio returns occur during the turbulent years 2008-2009. The results for the largest significant biases in portfolio variance are mixed; however 6 out of 9 significant biases occur between November 2007 and August 2011. "** denotes significance at 10\% significance level, that is, when the range from the 5 th percentile to the 95 th percentile of estimated biases in portfolio statistics for a given year does not contain zero. For presentation purposes, bias in variance is presented as a percentage.

autocorrelated because of non-synchronous trading (e.g., Fisher [1966]) or bid-ask spreads (e.g., Roll [1984], Jegadeesh and Titman [1995]). Our evidence precludes us from drawing the same conclusion. Given that our sample comprises the largest 501 stocks in the U.S. financial markets, non-synchronous trading or bid-ask spreads might not be an issue, at least for daily or lower frequencies. Consistent with the previous literature (Lo and Mackinlay [1990], Mech [1993], Canina et al. [1998]) we observe, on average, positive first-order autocorrelations ${ }^{29}$ in portfolios for the first half of our sample. ${ }^{30}$ However, following the financial crisis associated with the bankruptcy of Lehman Brothers in September 2008 and the subsequent period of turmoil in the U.S., we observe negative first-order autocorrelations in portfolio returns. The second- and third-order autocorrelations in portfolios are negative on average, which is in

\footnotetext{
${ }^{29}$ The results for autocorrelations are not reported here, but are available from the authors upon request.

${ }^{30}$ Transaction costs cause portfolio returns to be autocorrelated by delaying price adjustment.
} 
line with the results reported in Canina et al. [1998]. The cross-sectional variance of average returns is stable for the first half of our sample, and becomes volatile starting from 2007, which corresponds to the start of the GFC and subsequent period of global recession.

Figure 4 shows bias in the portfolio mean return, Bias $^{E}$, and bias in the portfolio variance, Bias $^{V}$, respectively, decomposed into its components as defined by Eq. (8) and Eq. (13). The terms that impact the mean return bias (left panel) include the autocovariance of average portfolio returns (Term 2, red line) and the term involving autocovariance of individual stock returns (Term 4, yellow line). In contrast, average portfolio returns (Term 1, blue line) and the term involving average individual stock returns (Term 3, green line) are negligible. The terms that impact bias in portfolio variance (right panel) include the covariance between the average portfolio returns $\bar{r}_{2}$ and the product $\bar{r}_{1} \bar{r}_{2}$ (Term 1, blue line), the variance of the product of portfolio returns $\bar{r}_{1} \bar{r}_{2}$ (Term 2, red line) and the term that depends on the variance of the sum of the product of individual stock returns $\sum_{i=1}^{N} r_{i, 1} r_{i, 2}$ (Term 3, green line). Conversely, the variance of the product of the average portfolio return and the sum of individual returns $\bar{r}_{1} \sum_{i=1}^{N} r_{i, 1} r_{i, 2}$ (Term 4, yellow line) can be neglected.

Transactions costs have important implications for the bias in portfolio mean returns, considering the amount of trading involved in the case of rebalanced portfolios. Liu and Strong [2008] discuss this issue and document four alternative estimates of transactions costs. In fact, from Eq. (8) we can directly observe the relationship between bias in the portfolio mean return and expected returns on both the portfolio and individual stocks. On the contrary, the portfolio variance bias in Eq. (13) relies solely on variances of the portfolio and individual stock returns, as well as intertemporal dependencies in these returns, with transactions costs having minimal influence on the bias.

In the next section we demonstrate that the optimal portfolio size required to obtain a well-diversified portfolio is heavily reliant on portfolio construction method especially for longer investment horizons.

\section{Implications for Portfolio Analysis}

In this section, we examine the implications variance bias can have for factor model inference as well as optimal portfolio size recommendations in achieving target diversification levels.

\subsection{Factor models inference}

In considering the implications of variance bias on inference in factor models we rely on the four-factor model of Carhart [1997]. We regress daily returns of simulated rebalanced and buy-and-hold portfolios on the asset pricing model common factors taken each year and over the period from 2003 to $2011 .{ }^{31}$ Our simulated portfolios are constructed from 50 assets

\footnotetext{
${ }^{31}$ The Fama-French data and momentum factor source is Kenneth French's web site at Dartmouth, see https: //mba.tuck.dartmouth.edu/pages/faculty/ken.french/data_library.html.
} 
Figure 5: BiAs in FACTOR MODEL ESTIMATES.
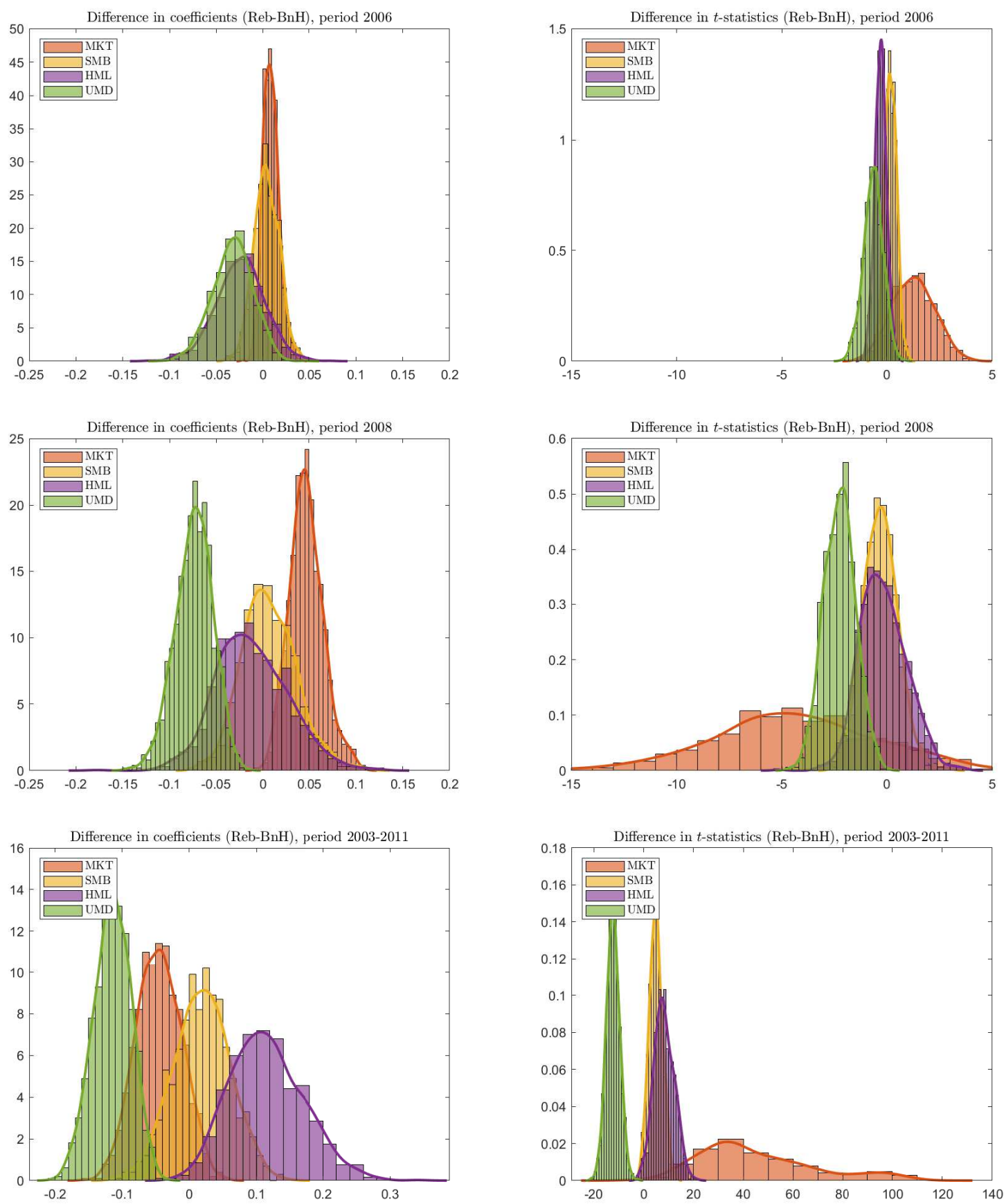

We contrast the factor model estimates and inference statistic of portfolios based on rebalanced strategy with the results from buy-and-hold approach. Left panels depict difference in estimated coefficients. Right panels show difference in $t$-statistic. The rebalancing is performed daily while the buy-and-hold portfolios are held for one year (the top and middle panels) or for the entire period (the bottom panel).

drawn 10,000 times without replacement keeping the selection identical for the rebalanced and buy-and-hold portfolios at each draw. We perform two sets of regressions using

$$
r_{k, t}=a_{i}+b_{i} M K T_{t}+c_{i} S M B_{t}+d_{i} H M L_{t}+e_{i} U M D_{t}+\varepsilon_{i t},
$$

where $r_{k, t}$ is the return in excess of the one-month Treasury bill rate on the rebalanced 
$(k=r e b)$ and buy-and-hold $(k=b h)$ portfolios. MKT is the excess return on the valueweighted aggregate market proxy; and $S M B, H M L$, and $U M D$ are returns on value-weighted, zero-investment, factor-mimicking portfolios for size, book-to-market equity, and one-year momentum in stock returns.

Figure 5 shows differences in estimated coefficients (left panels) and corresponding $t$ statistics (right panels) for years 2006 (top panels) and 2008 (middle panels) as well as for the entire period (bottom panels). Earlier, in Figure 2, we identified years 2006 and 2008 as the periods of the least and the most bias in portfolio variances when rebalanced portfolios are contrasted with buy-and-hold portfolios. Our results indicate that UMD is the most affected factor in terms of the difference in the estimated coefficients as well as the difference in its significance. We summarise the results of all single-year periods as well as the entire period in Table $3 .{ }^{32}$ As expected, MKT, a highly significant variable with the average $t$-statistic of 65-70, showed no difference in proportion of significant estimates in our simulations. Other factors proved to be more susceptible to changes in the rebalancing assumption. The results in Table 3 indicate that UMD factor exhibits the largest change in the number of significant estimates, making it the prime candidate for spurious inference in four-factor models.

\subsection{Portfolio diversification}

For convenience, fixed weight strategy is often employed when calculating portfolio returns, inadvertently matching the portfolio rebalancing frequency with that of available data. If the data are daily, such frequent rebalancing may not be viable or grossly misrepresent the actual strategy implemented, resulting in wrong inference. We wish to emphasize, however, that the purpose of this study is not to advocate the use of rebalancing or buy-and-hold portfolio strategy, but merely to use these two extreme cases to assess and contrast the variance of portfolio returns based on these two distinct strategies.

In this section, we discuss the importance of the variance biases in determining the optimal number of holdings in well-diversified portfolios. We investigate the consequences of adopting fixed weight and buy-and-hold strategies, in regards to systematic risk assessment, portfolio diversification and market regime under consideration (relatively calm periods such as 2003 vs. more turbulent times such as during the 2008 financial crisis). Previous literature often employs a simplified portfolio return decomposition, involving rebalancing the portfolio at the beginning of each time period back to the initial weights (see, Evans and Archer, 1968, Wagner and Lau, 1971, Tang, 2004, Kryzanowski and Singh, 2010, Chong and Phillips, 2013, among others). These studies underestimate the number of stocks required to achieve a certain level of portfolio diversification in buy-and-hold portfolios. Intuitively, this can be inferred from Figure 1 where a buy-and-hold portfolio initially comprised of 10 stocks, eventually resembles characteristics of a two-stock portfolio. In this section, using portfolio simulation we investigate the optimal size of portfolios based on the two approaches: fixed

\footnotetext{
${ }^{32}$ We include Figure 7 in the appendix where we used 2008 as an exemplar year to showcase our estimation procedure in more detail.
} 


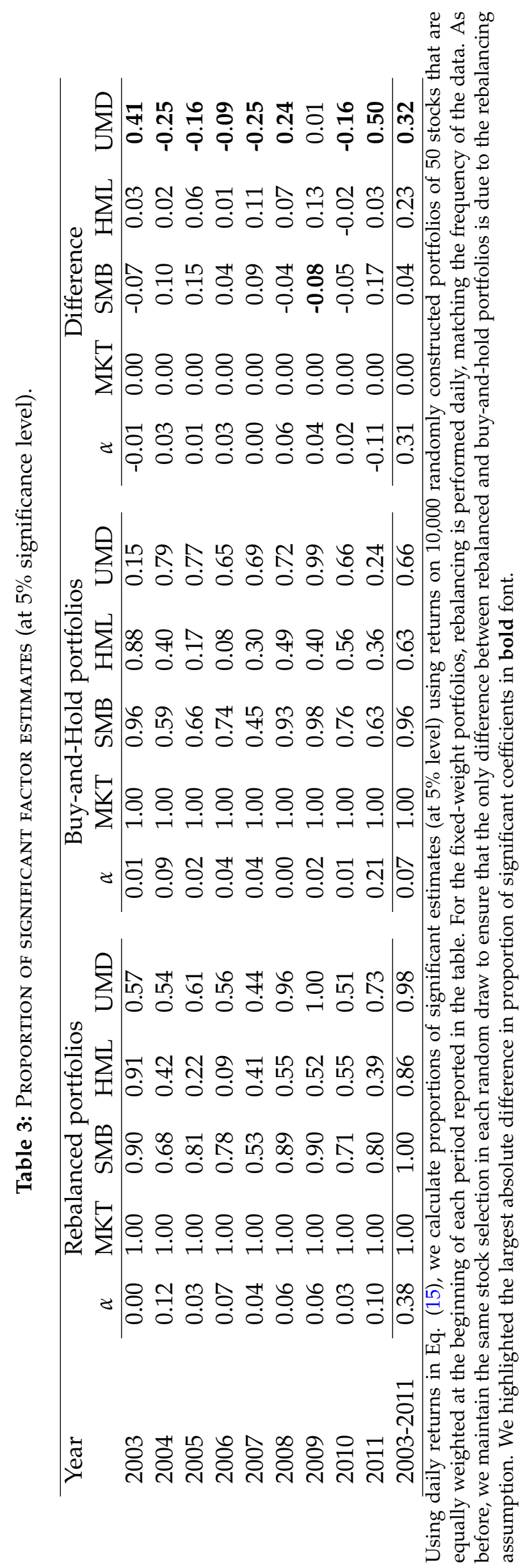


weight and buy-and-hold strategies.

We document that different number of holdings are required to reach a certain level of portfolio diversification. While fixed weight portfolio will maintain its diversification potential throughout a period, the buy-and-hold portfolio will start to diverge over time. Our analysis in Section 3 highlights that the portfolio risk does depend on the rebalancing strategy and may vary substantially in certain periods.

Figure 6 shows the reduction in diversifiable risk as the number of holdings in a portfolio increases. We perform the analysis year-by-year (relatively calm period of 2003 and a more turbulent 2008 year are used as exemplar periods and are included in the top and middle panels, respectively) and over the entire period (bottom panel). In the left panels of Figure 6 the vertical axis depicts portfolio risk measured by the annualised standard deviation, $\sigma_{n}$ where $n=1, \ldots, N .^{33}$

Based on Alexeev and Dungey [2015], we define a normalised risk measure that takes values between zero, for fully diversified portfolios, and one, for single-stock portfolios, as

$$
\Omega_{n}=\frac{\sigma_{n}-\sigma_{N}}{\sigma_{1}-\sigma_{N}}
$$

where $\sigma_{1}$ represents a single-stock portfolio risk, $\sigma_{N}$ is the market risk computed using all $N$ stocks. The results reported in Figure 6 (panels on the right) demonstrate that different number of stocks is required depending on the time period and rebalancing assumption. As it is evident from the figure, the number of portfolio holdings differ under the two scenarios, pointing the fact that the two investment assumptions should be considered carefully. Although the difference in the number of stocks required to achieve diversification appears insignificant when comparing fixed weight and buy-and-hold strategies in individual years (top and middle panels), this difference becomes highly pronounced when investigating the entire period (bottom panel). In contrast to previous literature that employs fixed weight approach and suggests that between 10 and 15 stocks are enough to provide adequate diversification, we find that when buy-and-hold strategy is assumed the recommended number of stocks is substantially higher. For example, during the 2003-2011 period, to achieve $90 \%$ diversification using fixed weight strategy, investors would hold 13 stocks, while for investors adopting a buy-and-hold approach the required number of stocks increases to 26 . This result reconfirms our findings that researchers and practitioners should take care in implementing the precise rebalancing strategy when calculating portfolio returns. Overall, one would expect that the longer the period under consideration the larger the difference in the number of stocks required will be to achieve diversification under the two rebalancing strategies. Alternatively, for the same investment horizon, the larger the discrepancy between data frequency employed in constructing decomposed portfolio returns and the frequency of the rebalancing used to construct portfolios, the larger will be the difference in recommended number of holdings to achieve same levels of portfolio diversification.

\footnotetext{
${ }^{33}$ Similar figures can be observed in seminal works by Evans and Archer [1968] and Solnik [1974].
} 
Figure 6: BIAS IN OPTIMAL PORTFOLIO SIZE.
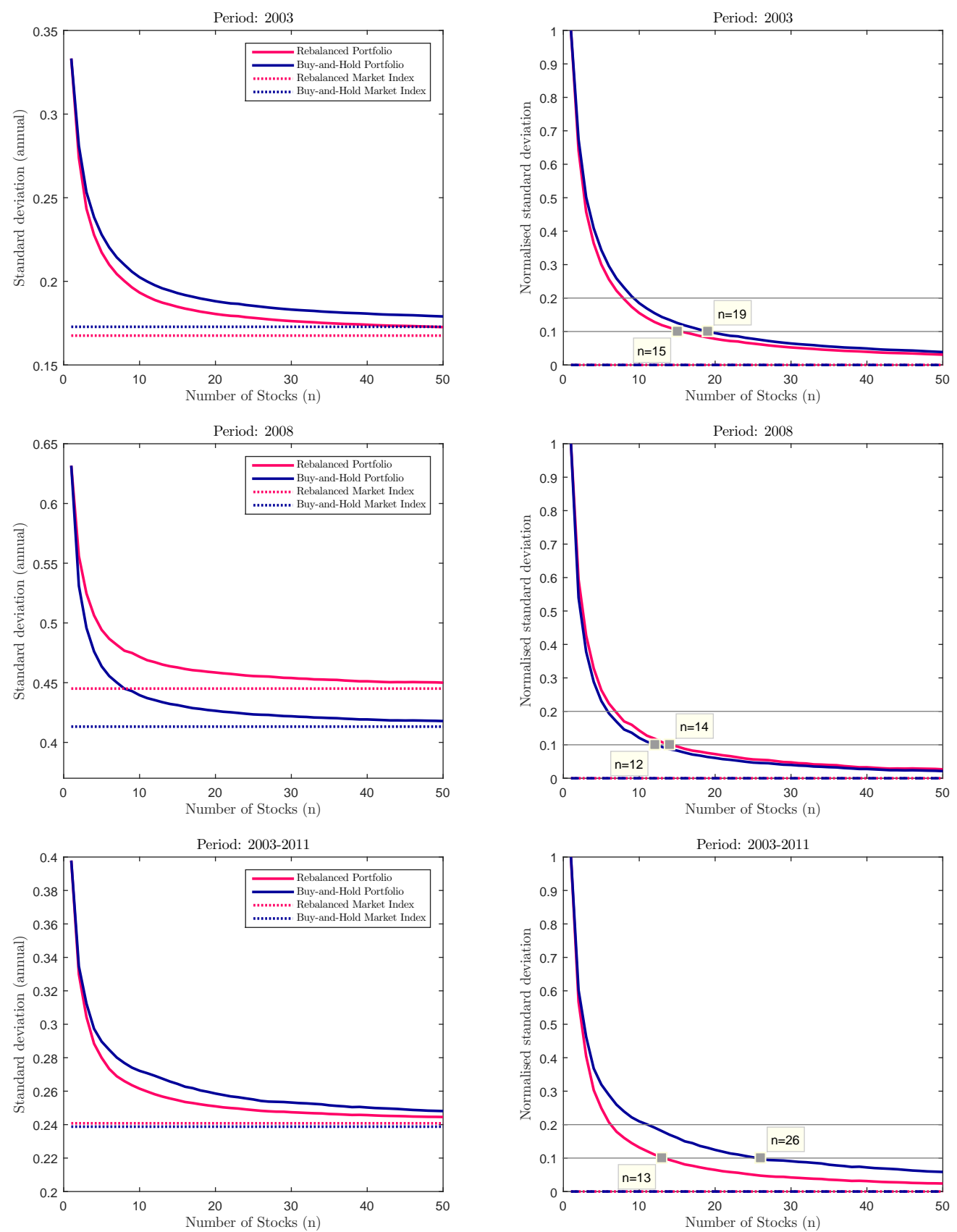

Left panels depict portfolio risk $\left(\sigma_{n}\right.$, solid lines) and the market risk $\left(\sigma_{N}\right.$, dotted horizontal lines) against the number of portfolio holdings. Diversifiable risk is defined as the difference between portfolio risk $\sigma_{n}$ (solid line) and the market risk $\sigma_{N}$ (dashed horizontal line) for rebalanced (red lines) and buy-and-hold (blue lines) portfolios, $\sigma_{n}-\sigma_{N}$. Right panels show the portfolio diversifiable risk as a percentage of the total diversifiable risk, $\Omega_{n}=\left(\sigma_{n}-\sigma_{N}\right) /\left(\sigma_{1}-\sigma_{N}\right)$. We contrast the results obtained using rebalanced strategy (red lines) with the results from buy-and-hold approach (blue lines). The rebalancing is performed daily while the buy-and-hold portfolios are held for one year (the top and middle panels) or for the entire period (the bottom panel). Horizontal grey lines at 0.2 and 0.1 represent $80 \%$ and $90 \%$ reduction in diversifiable risk, respectively.

\section{Conclusion}

Rebalancing is an essential component of the portfolio management process. The assumption of continuous rebalancing, although impractical, has gained popularity among researchers due to its simplicity and tractability. Significant biases in portfolio mean returns and 
portfolio variances arise as a consequence of incorrectly adopting a rebalancing assumption in estimating multi-period portfolio returns for buy-and-hold investors. Although such misalignments are rare in the finance literature, adaptation of rebalancing frequency matching that of the underlying data is quite frequent. In analysing bias in decomposed portfolio mean returns, Liu and Strong [2008] define return bias as the difference between mean returns of portfolios constructed using the rebalanced and buy-and-hold assumptions. They show that return bias can have detrimental consequences and results in misleading conclusions on momentum profits. Focusing on the second moment of return distributions, we compute variance bias as the difference between the variance of portfolios constructed using rebalanced returns and the decomposed buy-and-hold returns. We show that variance bias is significant and systematic. We demonstrate that the assumption of continuously rebalanced versus buy-and-hold weights have consequences for the optimal number of portfolio holdings recommendation in diversified portfolios. In light of the evidence on existence of bias in portfolio mean returns as well as variance, evaluation of portfolio risk-adjusted performance may be affected.

In our empirical exercise we avoid restrictive assumptions used to derive the closed form solution and examine biases arising in the means and variances of portfolios using equally weighted rebalanced and buy-and-hold portfolios of various sizes constructed from S\&P 500 constituents over the nine-year sample period ranging from January 2, 2003 to December 30, 2011. Allowing the number of stocks in portfolios to vary between 1 and 80 , we find that the bias in portfolio variance approaches an asymptotic value for portfolios in excess of 50 assets, pointing to a systematic nature of the bias. Our results (the sign of the bias and its significance) depend on the period under consideration with its specific time-series properties for both the portfolio returns and the individual stock returns. In particular, we find that negative variance biases tend to occur during 2003, 2005 and 2010 indicating that rebalancing of portfolios understates portfolio variances. Significantly positive biases are attributed to more turbulent 2008 and 2011, indicating that the rebalancing strategy overstates the buyand-hold strategy during these times. This result is not surprising since to maintain equal portfolio weights for stocks in a portfolio at each time, an investor will have to adopt a buying "losers" and selling "winners" strategy, resulting in a portfolio with elevated volatility and, subsequently, positive variance biases compared to a buy-and-hold portfolio. We observe the largest significant biases in portfolio returns between 2007 and 2011, corresponding to the turbulent period of the GFC, followed by the global recession. The existence of large biases in the variance of portfolios during adverse economic conditions suggests that rebalancing might not be an optimal investment strategy in crisis (and perhaps post-crisis) periods, and a buy-an-hold strategy should be considered as a viable alternative during these times.

When explaining bias in portfolio mean returns and variances, we find that higher crosssectional variability in average portfolio returns results in higher biases. Other variables contributing to the explanation of these biases include autocovariances of average portfolio 
returns and autocovariances of individual stock returns. Furthermore, when analysing bias decomposition, we observe that the autocovariance of average portfolio returns and the autocovariance of individual stock returns impact the return bias; whereas the bias in portfolio variance is influenced by the intertemporal dependencies in both the portfolio and individual stock returns. The purpose of this study is not to advocate the use of rebalancing or buy-andhold portfolio strategy, but merely to use these two extreme cases to assess and contrast the variance of portfolio returns based on these two distinct strategies. While the difference in some periods is negligible, we show that there are periods where the difference in the variance of these two strategies is significant and has consequences for factor model inference and optimal portfolio size recommendations.

Overall, the existence of portfolio variance biases have important implications not only when evaluating portfolio risk, but also in measuring portfolio performance. In addition, these variance biases adversely affect statistical inference in factor models. Our results indicate that one should exercise caution and apply correct assumption on portfolio weight dynamics when dealing with multi-period portfolio returns, as biases in portfolio variances and portfolio mean returns can lead to spurious results when analysing investment strategies or testing asset pricing models. We emphasise that researchers might fall into a methodological trap when observing (possibly insignificant) biases in portfolio returns and ignoring second moments, that may, in fact, include large biases. The existence of portfolio variance biases, particularly during the turbulent periods of financial crises and global recessions, might have important implications when evaluating portfolio risk-adjusted performance. We show that under the buy-and-hold strategy, the recommended portfolio sizes required for well-diversified portfolios may be substantially larger than previously recommended in the finance literature based on results that employ fixed weight portfolio construction approach.

\section{References}

D.-H. Ahn, J. Conrad, and R.F. Dittmar. Risk adjustment and trading strategies. Review of Financial Studies, 16:459-486, 2003.

V. Alexeev and M. Dungey. Equity portfolio diversification with high frequency data. Quantitative Finance, 15(7):1205-1215, 2015.

V. Alexeev and F. Tapon. The number of stocks in your portfolio should be larger than you think: Diversification evidence from five developed markets. Journal of Investment Strategies, 4(1):43-82, 2014.

M. E. Blume and R. F. Stambaugh. Biases in computed returns: An application to the size effect. Journal of Financial Economics, 12:387-404, 1983.

B. Branch and W. Freed. Bid-ask spreads on the AMEX and Big Board. Journal of Finance, 32: 159-163, 1977. 
J. Y. Campbell, A. W. Lo, and A. C. MacKinlay. The Econometrics of Financial Markets. Princeton University Press, 1997.

L. Canina, R. Michaely, R. Thaler, and K. Womack. Caveat compounder: A warning about using the daily CRSP equal-weighted index to compute long-run excess returns. The Journal of Finance, 53(1):403-416, 1998.

M. Carhart. On persistence in mutual fund performance. Journal of Finance, 52:57-82, 1997.

L. K. C. Chan, H.-L. Chen, and J. Lakonishok. On mutual fund investment styles. Review of Financial Studies, 15:1407-1437, 2002.

James Chong and G. Michael Phillips. Portfolio size revisited. Journal of Wealth Management, 15(4):49-60, 2013.

R. B. Cohen, J. D. Coval, and L. Pastor. Judging fund managers by the company they keep. Journal of Finance, 60:1057-1096, 2005.

J. Conrad and G. Kaul. Long-term market overreaction or biases in computed returns? Journal of Finance, 48:39-63, 1993.

K. Daniel, M. Grinblatt, and S. Titman. Measuring mutual fund performance with characteristic-based benchmarks. Journal of Finance, 52:1035-1058, 1997.

V. DeMiguel, L. Garlappi, and R. Uppal. Optimal versus naive diversification: How inefficient is the 1/N portfolio strategy? Review of Financial Studies, 22:1915-1953, 2009.

K.B. Diether, K.-H. Lee, and I.M. Werner. Short-sale strategies and return predictability. The Review of Financial Studies, 22:575-607, 2009.

M. Dungey, M. Luciani, and D. Veredas. Ranking Systemically Important Financial Institutions. Working Papers ECARES 2013/130530, ULB - Universite Libre de Bruxelles, 2012.

E. J. Elton and M. J. Gruber. Risk reduction and portfolio size: An analytic solution. Journal of Business, 50:415-437, 1977.

John L. Evans and Stephen H. Archer. Diversification and the reduction of dispersion: An empirical analysis. The Journal of Finance, 23(5):pp. 761-767, 1968.

E.F. Fama and K.R. French. Multifactor explanations of asset pricing anomalies. Journal of Finance, 51:55-84, 1996.

Eugene F. Fama and Kenneth R. French. Value versus growth: The international evidence. The Journal of Finance, 53(6):1975-1999, 1998.

L. Fisher. Some new stock market indices. Journal of Business, 29:191-225, 1966. 
B. Graham and J. Zweig. The Intelligent Investor: The Definitive Book on Value Investing. HarperBusiness Essentials, revised 1973 edition edition, 2003.

P. Gray. Stock weighting and nontrading bias in estimated portfolio returns. Accounting and Finance, 54:467-503, 2014.

K. Hou, G.A. Karolyi, and B-C. Kho. What factors drive global stock returns? Review of Financial Studies, 24(8):2527-2574, 2011.

W. Huang, Q. Liu, G. Rhee, and L. Zhang. Return reversals, idiosyncratic risk, and expected returns. Review of Financial Studies, 23(1):147-168, 2010.

N. Jegadeesh and S. Titman. Short horizon return reversals and the bid-ask spread. Journal of Financial Intermediation, 4:116-132, 1995.

G. Kaul and M. Nimalendran. Price reversals: Bid-ask errors or market overreaction. Journal of Financial Economics, 28:67-93, 1990.

Lawrence Kryzanowski and Singh Singh. Should minimum portfolio sizes be prescribed for achieving sufficiently well-diversified equity portfolios? Frontiers in Finance and Economics, 7(2):1-37, 2010.

C. M. C. Lee and B. Swaminathan. Price momentum and trading volume. Journal of Finance, 55:2017-2069, 2000.

W. Liu. A liquidity augmented capital asset pricing model. Journal of Financial Economics, 82: 631-671, 2006.

W. Liu and N. Strong. Biases in decomposing holding-period portfolio returns. The Review of Financial Studies, 21(5):2243-2274, 2008.

A. W. Lo and A. C. Mackinlay. When are contrarian profits due to stock market overreaction? Review of Financial Studies, 3:175-205, 1990.

Michael McAleer and Marcelo C. Medeiros. Realized Volatility: A Review. Econometric Reviews, 27(1-3):10-45, 2008.

T. S. Mech. Portfolio return autocorrelation. Journal of Financial Economics, 34:307-344, 1993.

R.E. Miller and A.K. Gehr. Sample size bias and sharpe's performance measure: A note. Journal of Financial and Quantitative Analysis, 13:943-946, 12 1978. ISSN 1756-6916.

S. Nagel. Short sales, institutional investors and the cross-section of stock returns. Journal of Financial Economics, 78:277-309, 2005.

R. Roll. A simple implicit measure of the effective bid-ask spread in an efficient market. Journal of Finance, 39:1127-1139, 1984. 
Bruno H. Solnik. Why not diversify internationally rather than domestically? Financial Analysts Journal, 30(4):48-54, 1974.

Gordon Y.N. Tang. How efficient is naive portfolio diversification? an educational note. Omega, 32(2):155 - 160, 2004.

M. Teo and S.-J. Woo. Style effects in the cross-section of stock returns. Journal of Financial Economics, 74:367-398, 2004.

Wayne H. Wagner and Sheila C. Lau. The effect of diversification on risk. Financial Analysts Journal, 27(6):pp. 48-53, 1971. 


\section{Appendix}

\section{A. Derivations}

Bias in portfolio returns

Using Eq. (5) and Eq. (3) for $\tau=2$, we can express the bias between the expected return of the rebalanced and the buy-and-hold portfolio as follows:

$$
\begin{aligned}
\operatorname{Bias}_{2}^{E} & =E\left(r_{r e b, 2}\right)-E\left(r_{b h, 2}\right) \\
& =E\left[\bar{r}_{2}\right]-E\left[\frac{1}{\sum_{j=1}^{N}\left(1+r_{j, 1}\right)} \sum_{i=1}^{N}\left(1+r_{i, 1}\right) r_{i, 2}\right] \\
& =E\left[\bar{r}_{2}\right]-E\left[\frac{1}{N\left(1+\bar{r}_{1}\right)}\left\{\sum_{i=1}^{N} r_{i, 2}+\sum_{i=1}^{N} r_{i, 1} r_{i, 2}\right\}\right] \\
& \approx E\left[\bar{r}_{2}\right]-E\left[\left(1-\bar{r}_{1}\right) \frac{1}{N}\left\{\sum_{i=1}^{N} r_{i, 2}+\sum_{i=1}^{N} r_{i, 1} r_{i, 2}\right\}\right] \\
& =E\left[\bar{r}_{2}\right]-E\left[\frac{1}{N} \sum_{i=1}^{N} r_{i, 2}+\frac{1}{N} \sum_{i=1}^{N} r_{i, 1} r_{i, 2}-\bar{r}_{1} \frac{1}{N} \sum_{i=1}^{N} r_{i, 2}-\bar{r}_{1} \frac{1}{N} \sum_{i=1}^{N} r_{i, 1} r_{i, 2}\right] \\
& =E\left[\bar{r}_{2}\right]-E\left[\bar{r}_{2}+\frac{1}{N} \sum_{i=1}^{N} r_{i, 1} r_{i, 2}-\bar{r}_{1} \bar{r}_{2}-\bar{r}_{1} \frac{1}{N} \sum_{i=1}^{N} r_{i, 1} r_{i, 2}\right] \\
& =E\left[\bar{r}_{1} \bar{r}_{2}-\left(1-\bar{r}_{1}\right) \frac{1}{N} \sum_{i=1}^{N} r_{i, 1} r_{i, 2}\right] \\
& =E\left[\bar{r}_{1} \bar{r}_{2}\right]-\frac{1}{N} \sum_{i=1}^{N} E\left[\left(1-\bar{r}_{1}\right) r_{i, 1} r_{i, 2}\right] .
\end{aligned}
$$

Assuming that $\bar{r}_{1}$ is uncorrelated with individual returns $r_{i, 1}$ and $r_{i, 2}$, Eq. (A.2) can be expressed as

$$
\begin{aligned}
\operatorname{Bias}_{2}^{E}= & E\left(\bar{r}_{1}\right) E\left(\bar{r}_{2}\right)+\operatorname{Cov}\left(\bar{r}_{1}, \bar{r}_{2}\right)-\frac{1}{N} \sum_{i=1}^{N} E\left(1-\bar{r}_{1}\right)\left[E\left(r_{i, 1}\right) E\left(r_{i, 2}\right)+\operatorname{Cov}\left(r_{i, 1}, r_{i, 2}\right)\right] \\
= & E\left(\bar{r}_{1}\right) E\left(\bar{r}_{2}\right)+\underbrace{\operatorname{Cov}\left(\bar{r}_{1,} \bar{r}_{2}\right)}_{>0}-\underbrace{E\left(1-\bar{r}_{1}\right)}_{>0} \frac{1}{N} \sum_{i=1}^{N} E\left(r_{i, 1}\right) E\left(r_{i, 2}\right) \\
& +\underbrace{[-\underbrace{E\left(1-\bar{r}_{1}\right)}_{>0} \frac{1}{N} \sum_{i=1}^{N} \underbrace{\operatorname{Cov}\left(r_{i, 1}, r_{i, 2}\right)}_{<0}]}_{>0} .
\end{aligned}
$$

Bias in portfolio variance

The variance bias between the rebalanced portfolio and the buy-and-hold portfolio is given by 


$$
\operatorname{Bias}_{2}^{V}=\operatorname{Var}\left(r_{r e b, 2}\right)-\operatorname{Var}\left(r_{b h, 2}\right),
$$

where the variance of the rebalanced portfolio is

$$
\operatorname{Var}\left(r_{r e b, 2}\right)=\operatorname{Var}\left[\bar{r}_{2}\right]=E\left[\bar{r}_{2}^{2}\right]-E\left[\bar{r}_{2}\right]^{2}
$$

and the variance of the buy-and-hold portfolio can be written as

$$
\begin{aligned}
\operatorname{Var}\left(r_{b h, 2}\right) & =\operatorname{Var}\left[\frac{1}{\sum_{j=1}^{N}\left(1+r_{j, 1}\right)} \sum_{i=1}^{N}\left(1+r_{i, 1}\right) r_{i, 2}\right] \\
& =\operatorname{Var}\left[\frac{1}{N\left(1+\bar{r}_{1}\right)}\left\{\sum_{i=1}^{N} r_{i, 2}+\sum_{i=1}^{N} r_{i, 1} r_{i, 2}\right\}\right] \\
& \approx \operatorname{Var}\left[\left(1-\bar{r}_{1}\right) \frac{1}{N}\left\{\sum_{i=1}^{N} r_{i, 2}+\sum_{i=1}^{N} r_{i, 1} r_{i, 2}\right\}\right] \\
& =\operatorname{Var}\left[\frac{1}{N} \sum_{i=1}^{N} r_{i, 2}+\frac{1}{N} \sum_{i=1}^{N} r_{i, 1} r_{i, 2}-\bar{r}_{1} \frac{1}{N} \sum_{i=1}^{N} r_{i, 2}-\bar{r}_{1} \frac{1}{N} \sum_{i=1}^{N} r_{i, 1} r_{i, 2}\right] \\
& =\operatorname{Var}\left[\bar{r}_{2}+\frac{1}{N} \sum_{i=1}^{N} r_{i, 1} r_{i, 2}-\bar{r}_{1} \bar{r}_{2}-\bar{r}_{1} \frac{1}{N} \sum_{i=1}^{N} r_{i, 1} r_{i, 2}\right] \\
& =\operatorname{Var}\left[\bar{r}_{2}\left(1-\bar{r}_{1}\right)+\left(1-\bar{r}_{1}\right) \frac{1}{N} \sum_{i=1}^{N} r_{i, 1} r_{i, 2}\right] \\
& =\operatorname{Var}\left[\left(1-\bar{r}_{1}\right)\left(\bar{r}_{2}+\frac{1}{N} \sum_{i=1}^{N} r_{i, 1} r_{i, 2}\right)\right] .
\end{aligned}
$$

In the third equality we applied an approximation $1 /\left(1+\bar{r}_{\tau}\right) \approx 1-\bar{r}_{\tau}$, as before, ignoring higher order terms in the Taylor series expansion. We can further rewrite Eq. (A.6) as follows:

$$
\begin{aligned}
\operatorname{Var}_{b h, 2}= & \operatorname{Var}\left(\bar{r}_{2}\right)+\frac{1}{N^{2}} \operatorname{Var}\left(\sum_{i=1}^{N} r_{i, 1} r_{i, 2}\right)+\operatorname{Var}\left(\bar{r}_{1} \bar{r}_{2}\right)+\frac{1}{N^{2}} \operatorname{Var}\left(\bar{r}_{1} \sum_{i=1}^{N} r_{i, 1} r_{i, 2}\right) \\
& +\frac{2}{N} \operatorname{Cov}\left(\bar{r}_{2}, \sum_{i=1}^{N} r_{i, 1} r_{i, 2}\right)-2 \operatorname{Cov}\left(\bar{r}_{2}, \bar{r}_{1} \bar{r}_{2}\right)-\frac{2}{N} \operatorname{Cov}\left(\bar{r}_{2}, \bar{r}_{1} \sum_{i=1}^{N} r_{i, 1} r_{i, 2}\right) \\
& -\frac{2}{N} \operatorname{Cov}\left(\bar{r}_{1} \bar{r}_{2}, \sum_{i=1}^{N} r_{i, 1} r_{i, 2}\right)-\frac{1}{N^{2}} \operatorname{Cov}\left(\sum_{i=1}^{N} r_{i, 1} r_{i, 2}, \bar{r}_{1} \sum_{i=1}^{N} r_{i, 1} r_{i, 2}\right) \\
& +\frac{2}{N} \operatorname{Cov}\left(\bar{r}_{1} \bar{r}_{2}, \bar{r}_{1} \sum_{i=1}^{N} r_{i, 1} r_{i, 2}\right) .
\end{aligned}
$$

Continuing with the assumption that portfolio returns are uncorrelated with the individual stock returns, Bias $_{2}^{V}$ for the variance reduces to 


$$
\begin{aligned}
\operatorname{Bias}_{2}^{V}= & \operatorname{Var}\left(r_{r e b, 2}\right)-\operatorname{Var}\left(r_{b h, 2}\right) \\
= & \operatorname{Var}\left(\bar{r}_{2}\right)-\operatorname{Var}\left(\bar{r}_{2}\right)-\frac{1}{N^{2}} \operatorname{Var}\left(\sum_{i=1}^{N} r_{i, 1} r_{i, 2}\right)-\operatorname{Var}\left(\bar{r}_{1} \bar{r}_{2}\right) \\
& -\frac{1}{N^{2}} \operatorname{Var}\left(\bar{r}_{1} \sum_{i=1}^{N} r_{i, 1} r_{i, 2}\right)+2 \operatorname{Cov}\left(\bar{r}_{2}, \bar{r}_{1} \bar{r}_{2}\right) \\
= & 2 \operatorname{Cov}\left(\bar{r}_{2}, \bar{r}_{1} \bar{r}_{2}\right)-\underbrace{\operatorname{Var}\left(\bar{r}_{1} \bar{r}_{2}\right)}_{>0}-\underbrace{\frac{1}{N^{2}} \operatorname{Var}\left(\sum_{i=1}^{N} r_{i, 1} r_{i, 2}\right)}_{>0}-\underbrace{\frac{1}{N^{2}} \operatorname{Var}\left(\bar{r}_{1} \sum_{i=1}^{N} r_{i, 1} r_{i, 2}\right)}_{>0} \text { (A.8) }
\end{aligned}
$$

Further simplification of Eq. (A.8) is possible only with additional restrictive assumptions, e.g., serial independence and normality. 
Algorithm 1 CONSTRUCTING SIMULATED PORTFOLIOS AND OBTAINING RESULTS.

1. Randomly select $N$ stocks out of all available stocks without replacement.

2. Given daily prices, $P_{i, \tau}, i=1, \ldots, N, \tau=0, \ldots, T$ calculate simple return for each stock selected in Step (1), $r_{i, \tau}, \tau=1, \ldots, T$.

3. Given selection in Step (1) and using Eqs. (1) and (3), calculate decomposed portfolio returns for rebalancing and buy-and-hold approaches, respectively.

4. Find expected value and variance for the two portfolios obtained in Step (3) and calculate associated biases using Eqs. (9) and (14) for $\tau=T$.

5. Repeat Steps (1)-(4) 10,000 times.

6. Based on results of Step (5) obtain mean, median, 5th and 95th percentiles for return and variance biases calculated in Step (4).

7. Repeat Steps (1)-(6) for the next period applying:

(a) (overlapping one year rolling windows) by moving a one-year estimation window one month at a time; used for Figures 3 and 4.

(b) (non-overlapping annual windows) by selecting price quotes from the last trading day of a previous year and to the last trading day of the current year for which the analysis is performed; used for Figure 2 and Table 1.

(c) (non-overlapping monthly windows) by selecting price quotes from the last trading day of a previous month and to the last trading day of the current month for which the analysis is performed; used for Table 2.

8. Repeat Steps (2)-(7) for other data frequencies (but track the selection of stocks in Step (1) in portfolios to avoid sample selection bias).

9. Repeat Steps 1-8 for each $N=1, \ldots, 80$. 


\title{
Supplementary Online Appendix
}

\author{
C. List of stocks
}

\begin{tabular}{|c|c|c|c|}
\hline RIC Code & Company Name & RIC Code & Company Name \\
\hline A.N & Agilent Technologies Inc & AA.N & Alcoa Inc \\
\hline AAPL.OQ & Apple Inc & ABC.N & AmerisourceBergen Corporation \\
\hline ABT.N & Abbott Laboratories & ACAS.OQ & American Capital Ltd \\
\hline ACE.N & ACE Limited & ACN.N & Accenture plc \\
\hline ADBE.OQ & Adobe Systems Inc & ADI.N & Analog Devices Inc \\
\hline ADM.N & Archer Daniels Midland Company & ADP.OQ & Automatic Data Processing Inc \\
\hline ADSK.OQ & Autodesk Inc & AEE.N & Ameren Corporation \\
\hline AEP.N & American Electric Power Co Inc & AES.N & The AES Corporation \\
\hline AET.N & Aetna Inc & AFL.N & AFLAC Inc \\
\hline AGN.N & Allergan Inc & AIG.N & American International Group Inc \\
\hline AIV.N & Apartment Investment \& Management Co & AIZ.N & Assurant Inc \\
\hline AKAM.Oq & Akamai Technologies Inc & AKS.N & AK Steel Holding Corporation \\
\hline ALL. $\mathrm{N}$ & The Allstate Corporation & ALTR.OQ & Altera Corp \\
\hline AM.N & American Greetings Corp & AMAT.OQ & Applied Materials Inc \\
\hline AMCC.OQ & Applied Micro Circuits Corp & AMD.N & Advanced Micro Devices Inc \\
\hline AMGN.OQ & Amgen Inc & AMT.N & American Tower Corporation \\
\hline AMZN.OQ & Amazoncom Inc & AN.N & AutoNation Inc \\
\hline ANF.N & Abercrombie \& Fitch Co & APA.N & Apache Corp \\
\hline APC.N & Anadarko Petroleum Corporation & APD.N & Air Products \& Chemicals Inc \\
\hline APH.N & Amphenol Corporation & APOL.OQ & Apollo Group Inc \\
\hline ARG.N & Airgas Inc & ASH.N & Ashland Inc \\
\hline ATI.N & Allegheny Technologies Inc & AVB.N & Avalonbay Communities Inc \\
\hline AVP.N & Avon Products Inc & AVY.N & Avery Dennison Corporation \\
\hline AXP.N & American Express Company & AZO.N & AutoZone Inc \\
\hline BA.N & Boeing Co & BAC.N & Bank of America Corporation \\
\hline BAX.N & Baxter International Inc & BBBY.OQ & Bed Bath \& Beyond Inc \\
\hline BBT.N & BB\&T Corporation & BBY.N & Best Buy Co Inc \\
\hline BC.N & Brunswick Corporation & BCR.N & CR Bard Inc \\
\hline BDX.N & Becton Dickinson and Company & BEN.N & Franklin Resources Inc \\
\hline BHI.N & Baker Hughes Incorporated & BIIB.OQ & Biogen Idec Inc \\
\hline BK.N & The Bank of New York Mellon Corporation & BLK.N & BlackRock Inc \\
\hline BLL.N & Ball Corporation & BMC.OQ & BMC Software Inc \\
\hline BMS.N & Bemis Company Inc & BMY.N & Bristol-Myers Squibb Company \\
\hline BRCM.OQ & Broadcom Corp & BSX.N & Boston Scientific Corporation \\
\hline BUT.N & Peabody Energy Corp & BWA.N & BorgWarner Inc \\
\hline BXP.N & Boston Properties Inc & C.N & Citigroup Inc \\
\hline CA.OQ & CA Technologies & CAG.N & ConAgra Foods Inc \\
\hline CAH.N & Cardinal Health Inc & CAM.N & Cameron International Corporation \\
\hline CAT.N & Caterpillar Inc & CB.N & The Chubb Corporation \\
\hline CBE.N & Cooper Industries plc & CBG.N & CBRE Group Inc \\
\hline CCE.N & Coca-Cola Enterprises Inc & CCL.N & Carnival Corporation \\
\hline CEG.N & Constellation Energy Group Inc & CELG.OQ & Celgene Corporation \\
\hline CERN.OQ & Cerner Corporation & CHK.N & Chesapeake Energy Corporation \\
\hline CHRQ.OQ & $\mathrm{CH}$ Robinson Worldwide Inc & CI.N & Cigna Corp \\
\hline CIEN.OQ & CIENA Corp & CINF.OQ & Cincinnati Financial Corp \\
\hline CL.N & Colgate-Palmolive Co & CLF.N & Cliffs Natural Resources Inc \\
\hline CLX.N & The Clorox Company & CMA.N & Comerica Incorporated \\
\hline CME.OQ & Comcast Corporation & CMI.N & CME Group Inc \\
\hline CMS.N & Cummins Inc & CMSCSA.OQ & CMS Energy Corp \\
\hline CNP.N & CenterPoint Energy Inc & CNX.N & CONSOL Energy Inc \\
\hline COF.N & Capital One Financial Corp & COG.N & Cabot Oil \& Gas Corporation \\
\hline COH.N & Coach Inc & COL.N & Rockwell Collins Inc \\
\hline COP.N & ConocoPhillips & COST.OQ & Costco Wholesale Corporation \\
\hline CPB.N & Campbell Soup Co & CPWR.OQ & Compuware Corporation \\
\hline CR.N & Crane Co & CRM.N & Salesforcecom \\
\hline CSC.N & Computer Sciences Corporation & CSCO.OQ & Cisco Systems Inc \\
\hline CSX.N & CSX Corp & CTAS.OQ & Cintas Corporation \\
\hline CTB.N & Cooper Tire \& Rubber Co & CTL.N & CenturyLink Inc \\
\hline CTSH.OQ & Cognizant Technology Solutions Corporation & CTXS.OQ & Citrix Systems Inc \\
\hline CVC.N & Cablevision Systems Corporation & CVG.N & Convergys Corporation \\
\hline CVH.N & Coventry Health Care Inc & CVS.N & CVS Caremark Corporation \\
\hline CVX.N & Chevron Corporation & D.N & Dominion Resources Inc \\
\hline DD.N & E I du Pont de Nemours and Company & DDR.N & DDR Corp \\
\hline DDS.N & Dillards Inc & DE.N & Deere \& Company \\
\hline DELL.OQ & Dell Inc & DF.N & Dean Foods Company \\
\hline DGX.N & Quest Diagnostics Inc & DHI.N & DR Horton Inc \\
\hline DHR.N & Danaher Corp & DIS.N & Walt Disney Co \\
\hline
\end{tabular}




\begin{tabular}{|c|c|c|c|}
\hline RIC Code & Company Name & RIC Code & Company Name \\
\hline DLTR.OQ & Dollar Tree Inc & DLX.N & Deluxe Corp \\
\hline DNB.N & Dun \& Bradstreet Corp & DNR.N & Denbury Resources Inc \\
\hline DO.N & Diamond Offshore Drilling Inc & DOV.N & Dover Corp \\
\hline DOW.N & The Dow Chemical Company & DRI.N & Darden Restaurants Inc \\
\hline DTE.N & DTE Energy Co & DTV.OQ & DIRECTV Inc \\
\hline DUK.N & Duke Energy Corporation & DV.N & DeVry Inc \\
\hline DVA.N & DaVita Inc & DVN.N & Devon Energy Corporation \\
\hline DYN.N & Dynegy Inc & EA.OQ & Electronic Arts Inc \\
\hline EBAY.OQ & eBay Inc & ECL.N & Ecolab Inc \\
\hline ED.N & Consolidated Edison Inc & EFX.N & Equifax Inc \\
\hline EIX.N & Edison International & EL.N & Estee Lauder Companies Inc \\
\hline EMC.N & EMC Corporation & EMN.N & Eastman Chemical Co \\
\hline EMR.N & Emerson Electric Co & EOG.N & EOG Resources Inc \\
\hline EP.N & El Paso Corp & EQR.N & Equity Residential \\
\hline EQT.N & EQT Corporation & ESRX.OQ & Express Scripts Inc \\
\hline ESV.N & Ensco plc & ETFC.OQ & E_TRADE Financial Corporation \\
\hline ETN.N & Eaton Corporation & ETR.N & Entergy Corporation \\
\hline EW.N & Edwards Lifesciences Corp & EXC.N & Exelon Corporation \\
\hline EXPD.OQ & Expeditors International of Washington Inc & EXPE.OQ & Expedia Inc \\
\hline F.N & Ford Motor Co & FAST.OQ & Fastenal Company \\
\hline FCX.N & Freeport-McMoRan Copper \& Gold Inc & FDO.n & Family Dollar Stores Inc \\
\hline FDX.N & FedEx Corporation & FE.N & FirstEnergy Corp \\
\hline FFIV.OQ & F5 Networks Inc & FHN.N & First Horizon National Corporation \\
\hline FII.N & Federated Investors Inc & FISV.OQ & Fiserv Inc \\
\hline FITB.OQ & Fifth Third Bancorp & FLIR.OQ & FLIR Systems Inc \\
\hline FLR.N & Fluor Corporation & FLS.N & Flowserve Corp \\
\hline FMC.N & FMC Corp & FMCC.OB & Federal Home Loan Mtg \\
\hline FNMA.OB & Fannie Mae & FRX.N & Forest Laboratories Inc \\
\hline FTI.N & FMC Technologies Inc & GAS.N & AGL Resources Inc \\
\hline GCI.N & Gannett Co Inc & GD.N & General Dynamics Corp \\
\hline GE.N & General Electric Company & GGP.N & Gilead Sciences Inc \\
\hline GILD.OQ & General Mills Inc & GIS.N & Corning Inc \\
\hline GLW.N & GameStop Corp & GME.N & Genworth Financial Inc \\
\hline GNW.N & Google Inc & GPC.N & Genuine Parts Company \\
\hline GPS.N & Gap Inc & GR.N & Goodrich Corp \\
\hline GS.N & The Goldman Sachs Group Inc & GT.N & Goodyear Tire \& Rubber Co \\
\hline GWW.N & WW Grainger Inc & HAL.N & Halliburton Company \\
\hline HAR.N & Harman International Industries Inc & HAS.O & Hasbro Inc \\
\hline HBAN.OQ & Huntington Bancshares Incorporated & HCBK.OQ & Hudson City Bancorp Inc \\
\hline HCN.N & Health Care REIT Inc & HCP.N & $\mathrm{HCP}$ Inc \\
\hline HD.N & The Home Depot Inc & HIG.N & Hartford Financial Services Group Inc \\
\hline HMA.N & Health Management Associates Inc & HNZ.N & H J Heinz Company \\
\hline HON.N & Honeywell International Inc & HOT.N & Starwood Hotels \& Resorts Worldwide Inc \\
\hline HP.N & Helmerich \& Payne Inc & HPQ.N & Hewlett-Packard Company \\
\hline HRB.N & H\&R Block Inc & HRL.N & Hormel Foods Corp \\
\hline HRS.N & Harris Corp & HSP.N & Hospira Inc \\
\hline HSY.N & Hershey Co & HUM.N & Humana Inc \\
\hline IACI.O & IAC_InterActiveCorp & IBM.N & International Business Machines Corp \\
\hline IFF.N & International Flavors \& Fragrances Inc & IGT.N & International Game Technology \\
\hline INTC.OQ & Intel Corporation & INTU.OQ & Intuit Inc \\
\hline IP.N & International Paper Co & IPG.N & The Interpublic Group of Companies Inc \\
\hline IR.N & Ingersoll-Rand Plc & IRM.N & Iron Mountain Inc \\
\hline ISRG.OQ & Intuitive Surgical Inc & ITT.N & ITT Corporation \\
\hline ITW.N & Illinois Tool Works Inc & JBL.N & Jabil Circuit Inc \\
\hline JCI.N & Johnson Controls Inc & JCP.N & J C Penney Company Inc \\
\hline JDSU.OQ & JDS Uniphase Corporation & JEC.N & Jacobs Engineering Group Inc \\
\hline JNJ.N & Johnson \& Johnson & JNPR.K & Juniper Networks Inc \\
\hline JNS.N & Janus Capital Group Inc & JNY.N & The Jones Group Inc \\
\hline JOY & Joy Global Inc & JPM.N & JPMorgan Chase \& Co \\
\hline JWN.N & Nordstrom Inc & K.N & Kellogg Company \\
\hline KBH.N & KB Home & KEY.N & KeyCorp \\
\hline KFT.N & Kraft Foods Inc & KIM.N & Kimco Realty Corporation \\
\hline KLAC.OQ & KLA-Tencor Corporation & KMB.N & Kimberly-Clark Corporation \\
\hline KMX.N & CarMax Inc & KO.N & The Coca-Cola Company \\
\hline KR.N & The Kroger Co & KSS.N & Kohls Corp \\
\hline L.N & Loews Corporation & LEG.N & Leggett \& Platt Incorporated \\
\hline LEH.N & Lehman Brothers & LEN.N & Lennar Corp \\
\hline LH.N & Laboratory Corp of America Holdings & LIFE.OQ & Life Technologies Corporation \\
\hline LIZ.N & Liz Claiborne Inc & LLL.N & L-3 Communications Holdings Inc \\
\hline LLTC.OQ & Linear Technology Corp & LLY.N & Eli Lilly \& Co \\
\hline LM.N & Legg Mason Inc & LMT.N & Lockheed Martin Corporation \\
\hline LNC.N & Lincoln National Corp & LOW.N & Lowes Companies Inc \\
\hline
\end{tabular}




\begin{tabular}{|c|c|c|c|}
\hline RIC Code & Company Name & RIC Code & Company Name \\
\hline LPX.N & Louisiana-Pacific Corp & LSI.N & LSI Corporation \\
\hline LTD.N & Limited Brands Inc & LUK.N & Leucadia National Corp \\
\hline LUV.N & Southwest Airlines Co & LXK.N & Lexmark International Inc \\
\hline MAR.N & Marriott International Inc & MAS.N & Masco Corporation \\
\hline MAT.O & Mattel Inc & MBI.N & MBIA Inc \\
\hline MCD.N & McDonalds Corp & MCHP.OQ & Microchip Technology Inc \\
\hline MCK.N & McKesson Corporation & MCO.N & Moodys Corp \\
\hline MDP.N & Meredith Corp & MDT.N & Medtronic Inc \\
\hline MET.N & MetLife Inc & MHP.N & The McGraw-Hill Companies Inc \\
\hline MHS.N & Medco Health Solutions Inc & MKC.N & McCormick \& Co Inc \\
\hline MMC.N & Marsh \& McLennan Companies Inc & MMM.N & $3 \mathrm{M} \mathrm{Co}$ \\
\hline MO.N & Altria Group Inc & MOLX.OQ & Molex Inc \\
\hline MON.N & Monsanto Co & MOS.N & The Mosaic Company \\
\hline MRK.N & Merck \& Co Inc & MRO.N & Marathon Oil Corporation \\
\hline MS.N & Morgan Stanley & MSFT.OQ & Microsoft Corporation \\
\hline MTB.N & M\&T Bank Corporation & MTG.N & MGIC Investment Corp \\
\hline MTW.N & Manitowoc Co Inc & MU.OQ & Micron Technology Inc \\
\hline MUR.N & Murphy Oil Corporation & MWV.N & MeadWestvaco Corporation \\
\hline MWW & Monster Worldwide Inc & MYL.OQ & Mylan Inc \\
\hline NBL.N & Noble Energy Inc & NBR.N & Nabors Industries Ltd \\
\hline NCR.N & NCR Corp & NDAQ.OQ & Nasdaq OMX Group Inc \\
\hline NE.N & Noble Corp & NEM.N & Newmont Mining Corp \\
\hline NFLX.OQ & Netflix Inc & NFX.N & Newfield Exploration Co \\
\hline NI.N & NiSource Inc & NKE.N & Nike Inc \\
\hline NOC.N & Northrop Grumman Corporation & NOV.N & National Oilwell Varco Inc \\
\hline NRG.N & NRG Energy Inc & NSC.N & Norfolk Southern Corp \\
\hline NTAP.OQ & NetApp Inc & NTRS.OQ & Northern Trust Corporation \\
\hline NU.N & Northeast Utilities & NUE.N & Nucor Corporation \\
\hline NVDA.OQ & NVIDIA Corporation & NVLS.OQ & Novellus Systems Inc \\
\hline NWL.N & Newell Rubbermaid Inc & NWSA.O & News Corp \\
\hline NYT.N & The New York Times Company & ODP.N & Office Depot Inc \\
\hline OI.N & Owens-Illinois Inc & OKE.N & ONEOK Inc \\
\hline OMC.N & Omnicom Group Inc & OMX.N & OfficeMax Incorporated \\
\hline ORCL.OQ & Oracle Corporation & ORLY.OQ & OReilly Automotive Inc \\
\hline OXY.N & Occidental Petroleum Corporation & PAYX.OQ & Paychex Inc \\
\hline PBCT.OQ & Peoples United Financial Inc & PBI.N & Pitney Bowes Inc \\
\hline PCAR.OQ & PACCAR Inc & PCG.N & PG\&E Corp \\
\hline PCL.N & Plum Creek Timber Co Inc & PCLN.OQ & pricelinecom Incorporated \\
\hline PCP.N & Precision Castparts Corp & PDCO.OQ & Patterson Companies Inc \\
\hline PEG.N & Public Service Enterprise Group Inc & PEP.N & Pepsico Inc \\
\hline PFE.N & Pfizer Inc & PFG.N & Principal Financial Group Inc \\
\hline PG.N & Procter \& Gamble Co & PGN.N & Progress Energy Inc \\
\hline PGR.N & Progressive Corp & PH.N & Parker Hannifin Corporation \\
\hline PHM.N & PulteGroup Inc & PKI.N & PerkinElmer Inc \\
\hline PLD.N & Prologis Inc & PLL.N & Pall Corp \\
\hline PMCS.OQ & PMC-Sierra Inc & PMTC.OQ & Parametric Technology Corporation \\
\hline PNC.N & PNC Financial Services Group Inc & PNW.N & Pinnacle West Capital Corporation \\
\hline POM.N & Pepco Holdings Inc & PPG.N & PPG Industries Inc \\
\hline PPL.N & PPL Corporation & PRGO.OQ & Perrigo Co \\
\hline PRU.N & Prudential Financial Inc & PSA.N & Public Storage \\
\hline PWER.OQ & Power-One Inc & PWR.N & Quanta Services Inc \\
\hline PX.N & Praxair Inc & PXD.N & Pioneer Natural Resources Co \\
\hline QCOM.OQ & QUALCOMM Incorporated & QLGC.OQ & QLogic Corp \\
\hline R.N & Ryder System Inc & RAI.N & Reynolds American Inc \\
\hline RDC.N & Rowan Companies Inc & RF.N & Regions Financial Corp \\
\hline RHI.N & Robert Half International Inc & RIG.N & Transocean Ltd \\
\hline RL.N & Ralph Lauren Corporation & ROK.N & Rockwell Automation Inc \\
\hline ROP.N & Roper Industries Inc & ROST.OQ & Ross Stores Inc \\
\hline RRC.N & Range Resources Corporation & RRD.OQ & RR Donnelley \& Sons Company \\
\hline RSG.N & Republic Services Inc & RSH.N & RadioShack Corp \\
\hline RTN.N & Raytheon Co & S.N & Sprint Nextel Corp \\
\hline SANM.OQ & Sanmina-SCI Corp & SBUX.OQ & Starbucks Corporation \\
\hline SCG.N & SCANA Corp & SE.N & Spectra Energy Corp \\
\hline SEE.N & Sealed Air Corporation & SHLD.OQ & Sears Holdings Corporation \\
\hline SHW.N & The Sherwin-Williams Company & SIAL.OQ & Sigma-Aldrich Corporation \\
\hline SJM.N & The J M Smucker Company & SLB.N & Schlumberger Limited \\
\hline SLE.N & Sara Lee Corp & SLM.O & SLM Corporation \\
\hline SNA.N & Snap-on Inc & SNDK.OQ & SanDisk Corp \\
\hline SNV.N & Synovus Financial Corp & SO.N & Southern Company \\
\hline SPG.N & Simon Property Group Inc & SPLS.OQ & Staples Inc \\
\hline SRCL.OQ & Stericycle Inc & SRE.N & Sempra Energy \\
\hline SSP.N & The E W Scripps Company & STI.N & SunTrust Banks Inc \\
\hline
\end{tabular}




\begin{tabular}{|c|c|c|c|}
\hline RIC Code & Company Name & RIC Code & Company Name \\
\hline STJ.N & St Jude Medical Inc & STR.N & Questar Corporation \\
\hline STT.N & State Street Corp & STZ.N & Constellation Brands Inc \\
\hline SUN.N & Sunoco Inc & SVU.N & SUPERVALU Inc \\
\hline SWK.N & Stanley Black \& Decker Inc & SWN.N & Southwestern Energy Co \\
\hline SWY.N & Safeway Inc & SYK.N & Stryker Corp \\
\hline SYMC.OQ & Symantec Corporation & SYY.N & Sysco Corp \\
\hline T.N & AT\&T Inc & TAP.N & Molson Coors Brewing Company \\
\hline TE.N & TECO Energy Inc & TER.N & Teradyne Inc \\
\hline TEX.N & Terex Corp & TGT.N & Target Corp \\
\hline THC.N & Tenet Healthcare Corp & TIE.N & Titanium Metals Corporation \\
\hline TIF.N & Tiffany \& Co & TIN.N & Temple-Inland Inc \\
\hline TJX.N & The TJX Companies Inc & TLAB.OQ & Tellabs Inc \\
\hline TMK.N & Torchmark Corp & TMO.N & Thermo Fisher Scientific Inc \\
\hline TNB.N & Thomas \& Betts Corp & TROW.OQ & T Rowe Price Group Inc \\
\hline TSN.N & Tyson Foods Inc & TSO.N & Tesoro Corporation \\
\hline TSS.N & Total System Services Inc & TUP.N & Tupperware Brands Corporation \\
\hline TWX.N & Time Warner Inc & TXN.N & Texas Instruments Inc \\
\hline TXT.N & Textron Inc & TYC.N & Tyco International Ltd \\
\hline UIS.N & Unisys Corporation & UNH.N & Unitedhealth Group Inc \\
\hline UNM.N & Unum Group & UNP.N & Union Pacific Corporation \\
\hline UPS.N & United Parcel Service Inc & URBN.OQ & Urban Outfitters Inc \\
\hline USB.N & U.S. Bancorp & UTX.N & United Technologies Corp \\
\hline VAR.N & Varian Medical Systems Inc & VFC.N & VF Corporation \\
\hline VLO.N & Valero Energy Corporation & VMC.N & Vulcan Materials Company \\
\hline VNO.N & Vornado Realty Trust & VRSN.OQ & VeriSign Inc \\
\hline VTR.N & Ventas Inc & VZ.N & Verizon Communications Inc \\
\hline WAG.N & Walgreen Co & WAT.N & Waters Corp \\
\hline WDC.N & Western Digital Corp & WEC.N & Wisconsin Energy Corp \\
\hline WFC.N & Wells Fargo \& Company & WFR.N & MEMC Electronic Materials Inc \\
\hline WFT.N & Weatherford International Ltd & WHR.N & Whirlpool Corp \\
\hline WLP.N & WellPoint Inc & WM.N & Waste Management Inc \\
\hline WMB.N & Williams Companies Inc & WMT.N & Wal-Mart Stores Inc \\
\hline WOR.N & Worthington Industries Inc & WPI.N & Watson Pharmaceuticals Inc \\
\hline WPO.N & The Washington Post Company & WY.N & Weyerhaeuser Co \\
\hline WYNN.OQ & Wynn Resorts Ltd & X.N & United States Steel Corp \\
\hline XEL.N & Xcel Energy Inc & XL.N & XL Group plc \\
\hline XLNX.OQ & Xilinx Inc & XOM.N & Exxon Mobil Corporation \\
\hline XRAY.OQ & DENTSPLY International Inc & XRX.N & Xerox Corp \\
\hline YHOO.OQ & Yahoo! Inc & YUM.N & Yum! Brands Inc \\
\hline ZION.OQ & Zions Bancorp & ZMH.N & Zimmer Holdings Inc \\
\hline
\end{tabular}


Figure 7: Distribution of $t$-statistic for the rebalanced and buy-and-hold portfolios for the 2008 period.
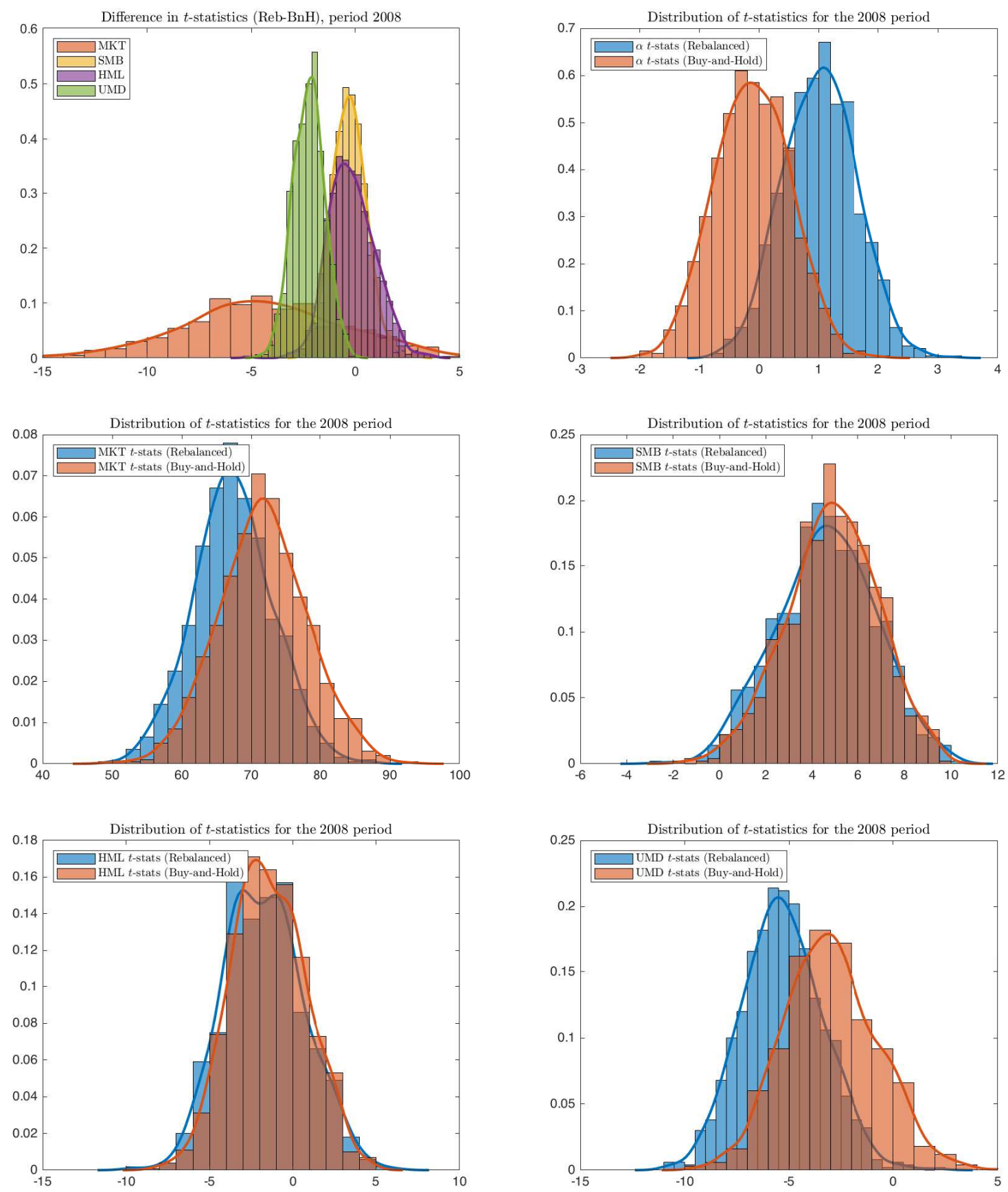

We use 2008 as an exemplar year to showcase our estimation procedure. Using Eq. (15) and 10,000 series of daily returns of rebalanced and buy-and-hold portfolios, we obtain 10,000 sets of intercept and slope estimates for the two portfolio strategies. We contrast the inference statistic of portfolios based on rebalanced strategy with the results from buy-and-hold approach. The top left panel shows the difference in $t$-statistic of the slope coefficients; the remaining panels contrast the $t$-distributions on case-by-case basis (e.g., the distribution of $t$-statistic of $\hat{\alpha}$ for buy-and-hold portfolio is plotted in red and centred around zero, while the distribution of $t$-statistic of $\hat{\alpha}$ for rebalanced portfolio is plotted in blue and centred around a positive value with a distinct shift in the centre of the distribution). 